UNIVERSITY OF GOTHENBURG

SCHOOL OF BUSINESS, ECONOMICS AND LAW

WORKING PAPERS IN ECONOMICS

No 620

\title{
Long-Run Cultural Divergence: \\ Evidence From the Neolithic Revolution
}

Ola Olsson and Christopher Paik

May 2015

ISSN 1403-2473 (print)

ISSN 1403-2465 (online) 


\title{
Long-Run Cultural Divergence: Evidence From the Neolithic Revolution *
}

\author{
Ola Olsson ${ }^{\dagger}$ \\ University of Gothenburg \\ Christopher Paik ${ }^{\ddagger}$ \\ NYU Abu Dhabi
}

May 4, 2015

\begin{abstract}
This paper investigates the long-run influence of the Neolithic Revolution on contemporary cultural norms and institutions as reflected in the dimension of collectivismindividualism. We outline an agricultural origins-model of cultural divergence where we claim that the advent of farming in a core region was characterized by collectivist values and eventually triggered the out-migration of individualistic farmers towards more and more peripheral areas. This migration pattern caused the initial cultural divergence, which remained persistent over generations. The key mechanism is demonstrated in an extended Malthusian growth model that explicitly models cultural dynamics and a migration choice for individualistic farmers. Using detailed data on the date of adoption of Neolithic agriculture among Western regions and countries, the empirical findings show that the regions which adopted agriculture early also value obedience more and feel less in control of their lives. They have also had very little experience of democracy during the last century. The findings add to the literature by suggesting the possibility of extremely long lasting norms and beliefs influencing today's socioeconomic outcomes.
\end{abstract}

Keywords: Neolithic agriculture, comparative development, Western reversal JEL Codes: N50, O43

\section{Introduction}

It is widely accepted that culture has strongly influenced patterns of economic development in countries around the world. More specifically, several studies have shown that the prevalence of individualistic norms, characterized by a strong belief in one's own ability and a preference for democratic governance, are positively associated with economic growth and lower risks of violence and war. Collectivist norms, characterized by in-group orientation and a high acceptance of traditional authority, have been shown to be less conducive to long-run economic development. ${ }^{1}$

\footnotetext{
${ }^{*}$ We would like to thank Romain Wacziarg, Saumitra Jha, Avner Greif, Jacob Shapiro, Carles Boix, Ernesto Dal Bo, Ran Abramitzky, James Fearon, Jonathan Bendor, Ian Hodder, Guido Tabellini, participants of ISNIE 2009 conference and the Haas School of Business Institutional Analysis Seminar participants for their comments and guidance. All errors are our own.

${ }^{\dagger}$ Email: ola.olsson@economics.gu.se

${ }^{\ddagger}$ Email: christopher.paik@nyu.edu

${ }^{1}$ See for instance the extensive recent empirical work of Thornhill and Fincher (2013), as well as Tabellini (2010), Gorodnichenko and Roland (2010, 2011), and Ashraf and Galor (2011b) within economics. Alesina and Giuliano (2014) provide an extensive overview of the literature.
} 
But why are some cultures primarily individualistic and others collectivistic? Two main hypotheses have recently been advanced in the literature to explain this pattern. First, a number of studies have concluded that the nature of social norms is linked to the specific conditions of agricultural production. In particular, it has been argued that farming based on irrigation easily gives rise to centrally coordinated production structures which, in turn, leads to collectivist cultural norms. Rain-fed agriculture, according to this view, requires less central coordination and is therefore associated with individualistic norms. ${ }^{2}$

Second, Fincher et al (2008) and Thornhill et al (2009) have advanced the so called pathogen prevalence-theory, arguing that people in regions that historically were more intensively exposed to infectious diseases tended to develop collectivist norms with an ingroup, conservative bias against strangers and influences from outside. Over the centuries, a more lethal disease environment gave rise to selective pressures that favored collectivist ideals. $^{3}$

In this paper, we argue that adverse collectivist cultural norms and institutions in the Western hemisphere have roots that can go even further back in time to the Neolithic revolution more than 10,000 years ago. We propose that both the nature of production and the prevalence of pathogens are primarily consequences of the transition from a hunter-gatherer survival strategy to a sedentary agricultural mode of production with a much higher population density. In addition to these two factors, the constant threat of predatory attacks from more primitive neighbors was yet another factor that favored collectivist cultural norms and suppression of individualistic expressions. We demonstrate that collectivist cultural norms and autocratic political institutions in Western regions and countries have a positive relationship with the time elapsed since the first transition to agriculture. People in regions that made a late transition to Neolithic agriculture instead value individualism, have a sense of control of their lives, and tend to live in stable democracies.

Our paper outlines an agricultural origins-model of cultural divergence where we argue for a persistent link between the agricultural transition and current culture/institutions. The model is set in the Malthusian modelling framework of Ashraf and Galor (2011b) with vertically transmitted cultural norms from parents to children. Internal and external influences might shift preferences to some degree towards more or less individualistic or collectivistic preferences. We propose that the original agricultural societies were typically strongly collectivist and autocratic. As discussed above, there were three main reason for this pattern: The collectivist nature of production, the prevalence of pathogens, and the

\footnotetext{
${ }^{2}$ The argument that irrigation was closely linked to hierarchical, "despotic" governments among the early riverine civilizations comes originally from Wittfogel (1957). Jones (1981) discuss the social implications of rain-fed agriculture. Benzen et al's (2013) empirical analysis demonstrates that irrigation is associated with less democracy and more stratified societies. In a recent article, Talhelm et al (2014) show that people in labor-intensive rice-growing regions within China are more prone to collectivist norms that people from rain-fed, wheat-growing regions.

${ }^{3}$ Gorodnichenko and Roland (2010) use genetic proximity to people in the United States as an instrument for individualist attitudes but do not explain why they are strong in America.
} 
threat of predation by neighboring primitive peoples.

Our analysis starts in an agricultural core region comprising both obedient collectivists as well as individualists where parents have paternalistic preferences for their offspring to share their own cultural values. The model describes how the strong collectivist cultural influences might eventually induce the individualists to consider leaving the core. Faced with the threat of steadily shrinking as a proportion of the population, the individualists prefer to migrate and colonize new lands despite the substantial direct costs and lower agricultural productivity that this is associated with. In the new land, there will be new tendencies towards collectivism as the pressures from production, pathogens and predation gradually increase in strength. Over time, the most determined individualists will self-select into once again colonizing new lands. In this manner, successive waves of migrating farmers move further and further away from the old agricultural core region and, in the process, become more and more individualistic-oriented in their values. Cultural and institutional differences with roots in the Neolithic have in this way persisted to the present day.

In support of the arguments above, this paper provides some empirical evidence for the persistence of the Neolithic impact on the current cultural and institutional differences. In our empirical analysis, we use data on 765 archaeological sites from Pinhasi et al. (2005) to create an approximate date of transition to agriculture for 64 countries, as well as 492 regions in 43 countries throughout the Western area. ${ }^{4}$ Collectivist attitudes are captured by questions from the World Value Survey regarding people's views on the importance of obedience and of having a sense of control of one's life. People who value obedience in child-raising and who do not feel to be in control of their own lives, are regarded as collectivists whereas people who value individual independence and who feel they have control of their own lives, are referred to as individualists. As a broad indicator of formal institutions that embody individualistic cultural values, we also use a variable capturing the cumulative experience of democracy during 1900-2000 from Gerring et al (2005).

The main results corroborate what evolutionary psychology and economic studies have suggested with regard to culture and economic performance: The possibility of extremely long-lasting norms and beliefs that continue to influence today's society. The empirical results show that regions which adopted agriculture early also value the virtues of obedience in general and have a weaker sense of being in control of their lives. These cultural views are also reflected in countries' formal institutions: Regions that made an early transition to agriculture have been far less democratic during the last century than countries that made a late transition. The results are robust to controlling for numerous historical and contemporaneous variables.

Our paper is related to many different strands of literature. Most obviously, our research is closely associated with Olsson and Paik (2013) and Lagerlöf (2013). The current paper provides a theoretical and empirical explanation to the reduced form negative re-

\footnotetext{
${ }^{4}$ Apart from in Olsson and Paik (2013), the data from Pinhasi et al has also been used by Ashraf and Michalopoulos (2011) and Hansen et al (2013).
} 
lationship between current GDP levels and the time since the Neolithic, which is the key feature in the papers above. Gorodnichenko and Roland (2013) present a model describing why societies with individualistic norms are more likely to adopt and maintain democratic governance. Bentzen et al. (2013) as well as Litina (2013) both focus on the need for irrigation in the old agricultural core regions but reach different conclusions. Unlike Benzen et al, Litina (2013) sees irrigation as the foundation for cooperation and trust. In general, the central importance of the Neolithic transition for understanding current levels of development has previously been emphasized by Diamond (1997), Olsson and Hibbs (2005), Putterman (2008) and others. ${ }^{5}$

The cultural and institutional development of Europe is a recurring theme in many influential works. ${ }^{6}$ Like Tabellini (2010), our study is focusing on long-run cultural divergence in a Western setting and two of our key outcome variables from the World Value Survey (control and obedience) are the same as in Tabellini's study. However, the long-run driver of cultural divergence in our paper is the differential timing of Neolithic agriculture rather than more recent historical levels of education and political institutions. Furthermore, our sample of European regions is more extensive than in Tabellini's work (492 vs $67)$.

The theoretical model of our paper uses the Malthusian growth framework developed by Ashraf and Galor (2011a). Our setup also includes the extension in Ashraf and Galor (2011b) that incorporates the Bisin and Verdier (2001) type of vertical cultural transmission dynamics. ${ }^{7}$ We extend this existing framework by including a decision by individualistic farmers whether to remain in the collectivist core or whether to colonize and introduce agriculture in a new land. ${ }^{8}$ Our model predicts that individualists will leave the core when the forces towards conformity and collectivism have reduced the proportion of individualists to a critical level beyond which they are better off as colonizers in a new land despite the significant costs and losses in terms of agricultural productivity that such

\footnotetext{
${ }^{5}$ For an overview of many of the most recent works on long-run development, see Spolaore and Wazciarg (2013).

${ }^{6}$ Classic works include North and Thomas (1973), Jones (1981), North (1990), Pomeranz (2000), Greif (2006) and Morris (2010). Blaydes and Chaney (2013) recently study the institutional impact of the emergence of feudal institutions during the 9th century. Building upon the work of Ashraf and Galor (2013), Becker et al. (2014) show that the heterogeneity in risk preferences within a country is positively associated with the level of genetic diversity, which in turn depends on the timing of the original settlement since the migration out of Africa. See also Acemoglu and Robinson (2012) for an overview of many of their recent articles on institutions and culture. Alesina and Giuliano (2014) reviews the most recent articles on the links between culture and institutions.

${ }^{7}$ In their empirical section, Ashraf and Galor (2011b) demonstrate that geographical isolation during pre-industrial times was associated with a relatively low cultural diversity and levels of prosperity today, whereas isolation was actually beneficial for economic development during the agricultural stage. The explanation to this pattern is that production in the agricultural era did not benefit much from diversity and individualism whereas industrial production did.

${ }^{8}$ The migration choice is somewhat related to the decision whether to form a new ethnic group or remain in the existing group, like in Ahlerup and Olsson (2012). The model in this paper is clearly distinguished from Ahlerup and Olsson (2012) since we model a migration decision among farmers rather than an ethnic fission in a hunter-gatherer population. The driver of cultural differences in the current model is the interplay between collectivist and individualistic norms whereas cultural differences in Ahlerup and Olsson (2012) are caused by a geographically induced "cultural drift" that limits effective communication between groups.
} 
a move implies.

We believe that the key contribution of our paper is the modelling of how agriculture spread through migration across the Western area by more and more individualistic farmers. We think that our model is potentially more broadly relevant for understanding also other historical migration episodes. For instance, it is well known that the settlement of America from $1500 \mathrm{CE}$ onwards was often carried out by groups that were not well integrated in their home countries and even refused to conform to the prevailing political or religious hegemony at the time. ${ }^{9}$ Although data for earlier periods are scarce, we believe our model might also serve as a point of reference for understanding important migration movements such as the Greek colonization of the Western Mediterranean in antiquity, the Austronesian settlement of islands in the Pacific Ocean, and the Viking expansion to the British Isles and into current Russia from about $800 \mathrm{CE}$.

The rest of the paper proceeds as follows. Section 2 introduces the series of arguments explaining in detail the long term cultural divergence theory, and Section 3 presents the model. For empirical support, Section 4 presents the data, Section 5 discusses the empirical strategy, and Section 6 presents the findings. Section 7 concludes with suggestions for relevant future research.

\section{Agricultural Origins and Cultural Divergence}

In this section, we outline an agricultural origins-theory explaining why areas that made a late transition to agriculture would come to be endowed with cultural norms and institutions that were relatively individualistic and non-conformist in nature. The theory also explains why countries and regions close to the origin of agriculture still today exhibit collectivist cultural norms and autocratic institutions.

The argument rests on three building blocks: 1) The original agricultural societies were strongly collectivist and autocratic. 2) Agriculture mainly spread throughout the Western lands through migration of individualistic farmers. 3) Cultural norms with roots in the Neolithic Revolution have persisted to the present day. We discuss each of these building blocks in turn below.

\subsection{Origin of Collectivist Agricultural Societies}

The earliest evidence of domesticated plants and animals date back to about 8500 BCE in the Fertile Crescent, encompassing parts of modern Israel, Jordan, Turkey, Syria, Iraq and Iran. The wild progenitors of grasses such as wheat and barley were domesticated first and somewhat later goats, pigs, horses and cattle. The new technology spread rapidly to other parts of the region. It was soon associated with a very sharp increase in population growth and a radical change in terms of social organization. Already by 8,000 BCE, it

\footnotetext{
${ }^{9}$ See for instance Abramitzky et al (2012) for a study of Norwegian migrants during the mass migration era 1850-1913. Their results indicate a negative selection into migration from urban areas in terms of individual income.
} 
is estimated that an agricultural village like Abu Hureyra in current Syria hosted about 5,000 individuals (Bellwood, 2005).

In our view, there are three primary factors explaining why the original agricultural societies in the Fertile Crescent were highly collectivist: i) The nature of production, (ii) the prevalence of pathogens, and (iii) the imminent threat of predation.

The most obvious change that the Neolithic Revolution brought was perhaps the nature of production. From having been nomadic hunter-gatherers, the first farmers were sedentary and lived in permanent village dwellings. Whereas hunter-gatherers were relatively egalitarian, lacking private property rights, the new agricultural mode of production encouraged the accumulation of wealth and a delineation of what property belonged to whom. A strong worship of ancestors, manifested in the practice of plastered skulls that were kept inside houses, indicate a strong awareness of kinship ties and perhaps also of inheritance within the family (Morris, 2010).

The early agricultural communities were hierarchical societies, led by powerful chiefs who over the centuries gradually transformed into divine kings. Some of the surplus from food production was amassed in public storage facilities. The king and his elite in control of such wealth could easily redistribute it to warriors under their command, acquire luxury goods, and construct impressive public monuments such as temples and palaces that further enhanced their prestige. Specialized workforces including craftsmen, warriors, priests, laborers, and nobilities emerged, all acting within a distinct hierarchy placing importance on order and loyalty. The rise of a non-working class and the need to feed these non-farmers with surplus produce, strongly contributed to the rise of extractive political systems with hierarchical orders (Wittfogel, 1957; Diamond, 2005).

As demonstrated further below, a first wave of migration out of the Fertile Crescent happened in the centuries after $7000 \mathrm{BCE}$. The addition of domesticated animals to the standard set of species at this time further increased the mobility of farmers who were unhappy with social developments in the core. The arid lands surrounding the rivers Euphrates and Tigris were settled by 6000 BCE (Bellwood, 2005). Agriculture in these areas were only possible through river irrigation and turned out to be even more demanding in terms of central coordination (Postgate, 1995). The riverbanks of the Nile in Egypt were settled about the same time, using similar irrigation practices of dykes, canals, and flood gates. Without centralized coordination, water management in these otherwise inhospitable areas could easily collapse and lead to disaster.

In his famous "hydraulic hypothesis", Wittfogel (1957) identified river irrigation to be the key factor behind the rise of strongly centralized and autocratic states. By this time, the emerging civilizations were further circumscribed by deserts and by neighboring areas that were already filled up by farming populations. People had nowhere to escape from the "beehive" communities in Mesopotamia and Egypt. This also contributed to the gradual centralization of power towards "proto-states" (Carneiro, 1970).

A second important factor behind the rise of collectivism in the early farming communities was the pests and plagues that came with agriculture. According to the "parasite 
model of democracy", developed by Fincher et al (2008) and Thornhill et al (2009), communities in places where the risk of infectious disease is significant tend to be characterized by typical collectivist features such as in-group cooperation, a low willingness to interact with strangers, conservative traditions, and authoritative leadership. Individual initiative is discouraged whereas obedience is rewarded. According to the theory, these collectivist norms are fundamentally a behavioral (and perhaps genetically transmitted) adaptation serving to minimize the risk of contagious disease. Analogously, in environments with a lower prevalence of pathogens, selection pressures are more in favor of individualistic behavior characterized by out-group cooperation, openness to new ideas and trade, and stronger individual freedom and rights.

Although the pioneering literature on pathogen prevalence and collectivism/individualism does not explicitly address the role of the Neolithic Revolution, a lot of evidence indeed suggests that early farming was strongly associated with the introduction of lethal crowd diseases. Diamond (1997) documents how several of the great pests such as smallpox, measles and influenza started to spread among humans in the densely populated, unhygienic farming villages where man and animals often shared quarters. Later killers such as the Bubonic Plague were spread by rats that naturally flourished in farming villages and large settlements. Infectious diseases like these could not be sustained among isolated hunter-gatherer societies and indeed only emerged after the transition to Neolithic agriculture. $^{10}$

A third reason for collectivism in the agricultural core area was the imminent threat of predation by neighboring peoples. The accumulation of harvests, domesticated animals, tools, pottery, women, and luxury goods in cities with temples and towers must have filled the neighboring nomadic peoples with awe and an irresistible temptation for looting or even conquest. The history of Mesopotamia, Syria and other regions in the Fertile Crescent are indeed full of episodes of attacks from foreign peoples, ranging from Amorites, Kassites and Arabs to Mongols. Societies that did not possess a strong military defense were unlikely to last for long. Applying the same logic as in the "parasite model" above, we argue that this constant threat of invasion contributed to further cement the various facets of collectivism and inhibit the emergence of individualism.

\section{$2.2 \quad$ Migration and Cultural Divergence}

Population pressure within the first farming communities soon induced people to colonize and settle in new lands. This migration meant that diffusion of agriculture happened mainly through physical movement of farmers from the origin of agriculture to other parts of the world (Bellwood, 2005; Cavalli-Sforza et al, 1994). The assumption of agriculture inducing population pressure and migration of people to new settlements, is drawn from

\footnotetext{
${ }^{10}$ When we run a regression with a measure of historical pathogen prevalence from Fincher et al (2008) as the dependent variable and time since the Neolithic transition as an explanatory variable for 44 countries with available data, we find a very strong and significant positive correlation, suggesting that the agricultural transition contributed importantly to the subsequent disease environment in countries. Results are available upon request.
} 
the widely accepted demic diffusion theory by Ammerman and Cavalli-Sforza (1984). The "demic diffusion" refers to a diffusionary process by population growth and physical movement of farmers. ${ }^{11}$ The Neolithic migrants conquered new lands and in the process often replaced aboriginal hunter-gatherers.

Some of the farmers who migrated out from the agricultural core in the Fertile Crescent shifted the agricultural frontier westward through across the Bosporus and into Europe. The farmers brought the package of domesticated plants and animals that they had developed in the Fertile Crescent. According to Bellwood (2005) and other sources, the advance of farming in the northerly direction came to a halt at the Hungarian plain from which agriculture did not spread for perhaps 600 years. The reasons for this delay are disputed but probably include both cultural and environmental explanations.

Figure 1 shows the distribution of the Average time since transition to agriculture among the 492 regions in our sample. The figure indicates a relatively steady rate of dispersion up until about $5500 \mathrm{BCE}$ when there was an unusually rapid spread into many regions, marked by the sudden peak in the distribution. The migrants followed the Danube onto the loess soils of the Rhineland and west towards the Paris basin. The new colonization was carried out by farmers with a different culture from before referred to as Linear Bandkeramik (LBK). The characteristics of this culture included settlements in longhouses along rivers, incised pottery and a package of plants and animals adapted to a temperate climate (Bellwood, 2005). In a few hundred years, this culture had settled a very large part of northwestern Europe in one big movement.

\section{Insert Figure 1}

However, in the coastlands of northern Germany and Poland, the Netherlands, Belgium and Denmark, farmers met strong resistance by non-farming communities living off the abundant aquatic resources in the area. Once again, there was a standstill in the agricultural expansion, as indicated by the fall in the distribution of newly settled regions in figure 2. When the farming lifestyle eventually continued spreading northward, reaching the Baltic Sea by 4500 BCE, the British isles by 4000 BCE and Sweden by 3500 BCE, the farmers mingled to a much greater extent with thriving existing hunter-gatherer cultures than in continental Europe.

Several key findings suggest that the culture of the colonizers gradually changed as the frontier moved northwestwards. Nothing similar to the cities or temples of Mesopotamia were found among the first farmers in the northwestern parts. With the sudden advance of the LBK-culture around $5500 \mathrm{BCE}$, there are instead strong indications of a relatively

\footnotetext{
${ }^{11}$ Support for the demic diffusion theory come from Bellwood (2005)'s work on the spread of ethnolinguistic groups, Cavalli-Sforza (1994)'s work on genetic spread and Bentley's work on looking at strontium isotope analysis of early Neolithic skeletons. For further evidence supporting the demic diffusion argument refer to Cavalli-Sforza et al (1994), Sokal (1991) and Pinhasi (2005). In genetics the demic diffusion is marked by clines of genetic spread moving northwest from the Middle East. Studies supporting the demic diffusion argument include Chikhi (2002), who finds an average contribution of between 50-65 percent by Near Eastern farmers to the European gene pool.
} 
egalitarian social structure where people lived together in timbered longhouses without clear social stratification. In the words of Bellwood (2005):

The longhouses...might have reflected non-lineage societies in which early landownership patterns were fluid - a pattern in which people could move frequently from one village or longhouse to another...Such a society can be characterized as oriented towards the acquisition of labor rather than land...Longhouses thus correlate from this perspective with a society in pioneer mode, where individual families need mobility. (Bellwood, 2005, p 77)

As farming spread even further northwards, the indications of a blending of farming and native hunter-gatherer populations explain why the tendencies towards an egalitarian social structure become even stronger. Among the populations of northern Europe, it appears to have been common even for farmers to leave their agricultural lifestyle during periods and instead subsist on hunted game. Such a shift would of course have been unthinkable in the overcrowded farming communities in the Fertile Crescent where land was generally more fertile.

Our interpretation of this evidence is that it is consistent with a model whereby it is mainly the individuals who are least integrated within their old community and who are most averse to collectivism, who decide to leave and colonize new lands even if the original lands are more fertile. As population grows over time within this new community, it will once again be the least integrated individuals who are most averse to the collectivist tendencies of the leadership who decide to move and shift the frontier further. In this way, the colonization of new lands and the implied introduction of Neolithic agriculture, are carried out by individuals who by a self-selection process become more and more individualistic in their values. Such a pattern is conducive to the historical cultural evidence showing less socially stratified farming communities among the northwestern regions that adopted agriculture thousands of years later than in the agricultural core regions.

\subsection{Long-Run Persistence of Culture and Institutions}

The long term persistence argument regarding culture and institutions rests on the assumption that once established, culture is much less capable of dramatic shifts as it is already entrenched (Posner, 1980). It follows directly from the works of North (1990), Tabellini (2010), Acemoglu and Robinson (2012) and others who argue that it takes long time to embed new routines, customs, traditions and conventions into an existing institution, even when formal rules change under external influence. Once a development path is set on a particular course, it is endogenous to the past and only marginal changes will be made by the players seeking immediate solutions to their problems; the result is often the persistence of inefficient government and culture detrimental to a civil society (North, 1990, Putnam, 1993).

This line of argument is also similar to the hypotheses testing the long term effects of historical institutions, technology and economic performance on current socioeconomic 
outcomes (Diamond, 1997; Comin et al, 2010; Putterman, 2008) or the even older impact of the original "Out-of-Africa"-migration on current levels of ethnic diversity (Ahlerup and Olsson, 2012) and levels of prosperity (Ashraf and Galor, 2013). Culture - like technology, institutions, and genetic markers - is resilient in nature and tend to be inherited from one generation to other.

\section{The model}

In this section, we outline an extended version of the Malthusian growth model of Ashraf and Galor (2011b) where cultural transmission follows a similar dynamics as in Bisin and Verdier (2001) and Boyd and Richerson (1985). Our contribution to the model lies in modelling a migration choice for people with individualistic norms in a farming population during the Malthusian era. Although the model is primarily intended to explain the gradual colonization of Europe by farmers from a collectivist core area, the theory might apply also to other historical population expansions such as the Bantu expansion in Africa, the ancient Greeks in the Mediterranean or the Austronesian colonization of islands in the Pacific Ocean.

The initial setting for the model is a continent where agriculture has recently emerged in a core region whereas all other regions are still populated by hunter-gatherers.

\subsection{The Malthusian model}

\subsubsection{Individuals}

Let us imagine an overlapping-generations framework with a representative individual in the agricultural core region. The individual lives for two periods, childhood and adulthood. All key choices are made in adulthood. The individual has a utility function given by

$$
u_{t}=c_{t}^{\gamma} \cdot\left(P_{t} n_{t}\right)^{1-\gamma}
$$

where $c_{t}$ is the individual's level of consumption at time $t$ with an associated preference parameter $\gamma, n_{t}$ is the (continuous) number of children of each adult person and $P_{t}$ is the probability that the grown-up children who are born at time $t$ share the same basic cultural norms as the parent when they have become adults at time $t+1$. One unit of time might thus be thought of as a generation.

People can be of two distinct cultural types; collectivist or individualist. Collectivist types are loyal and obedient to authorities in society including parents and kings and easily conform to the prevailing norms in society. They stay away from strangers and are prone to adopt an ethnocentric view of the world. Individualistic cultural types refuse to conform to the norms of the collectivists and want to do things their own way. They are open to out-group cooperation, have a more egalitarian social structure, and do not necessarily follow traditional leaders. 
An important assumption in the utility function is that parents have paternalistic preferences in the sense that they have a strong preference for their children to be of the same cultural type as themselves. For simplicity, a parent is assumed to get zero utility in the event that her children adopt a different cultural norm from that of herself (which happens with a probability $1-P_{t}$ ). The dynamics of this cultural transformation will be explained further below.

The adult individual earns a wage income $w_{t}$ which can be used for either child rearing or consumption. ${ }^{12}$ The budget constraint is therefore

$$
c_{t}+\tau n_{t} \leq w_{t}
$$

where $\tau$ is the cost of rearing one child. Combining (1) and the budget constraint gives us an optimization problem for the choice of $n_{t}$ :

$$
n_{t}^{*}=\arg \max \left[\left(w_{t}-\tau n_{t}\right)^{\gamma} \cdot\left(P_{t} n_{t}\right)^{1-\gamma}\right] .
$$

From the first-order conditions, it is straightforward to show that the utility maximizing quantity of children is

$$
n_{t}^{*}=\frac{(1-\gamma) w_{t}}{\tau} .
$$

Since the adult population in the next generation is $L_{t+1}=n_{t}^{*} L_{t}$, we can express the law of motion for labor as:

$$
L_{t+1}=n_{t}^{*} L_{t}=\frac{(1-\gamma) w_{t} L_{t}}{\tau}
$$

\subsubsection{Production}

The aggregate production function for agriculture during the Malthusian era is given by

$$
Y_{t}=(A X)^{1-\alpha} \cdot L_{t}^{\alpha}
$$

In this function, $Y_{t}$ is output, $X$ is the amount of land and $A$ is its general productivity, $L_{t}$ is the size of the labor force (equal to the number of live adults in period $t$ ), and $\alpha \in(0,1)$ is the output elasticity of labor. For simplicity, we follow the convention of normalizing the amount of land to $X=1$. There are no property rights to land so holders of land receive no compensation.

The market for labor is competitive and workers are paid their average product, which will also be equal to the equilibrium income per person:

$$
w_{t}^{*}=\left(\frac{A}{L_{t}}\right)^{1-\alpha}=\frac{Y_{t}}{L_{t}}=y_{t}^{*} .
$$

\footnotetext{
${ }^{12}$ Wages should not be thought of as modern wages at the end of the month but rather as in-kind returns for work effort.
} 
Wages thus increase with land productivity and decrease with the size of the working population at time $t$.

\subsubsection{The evolution of cultural norms}

The key part of the model concerns the evolution of cultural norms. Let us assume that there is a fraction of $\omega_{t}$ individualists in the population $L_{t}$ whereas a fraction $1-\omega_{t}$ are collectivists. The collectivists are in majority at time $t$ since their willingness to obey a central coordinating leadership is one of the key reasons why they have been able to create an early cohesive agricultural society in the first place. Hence, our starting point is that $\omega_{t}<1 / 2$.

However, children to both collectivist and individualistic parents are potentially subject to cultural influences from the adults in the rest of the society. ${ }^{13}$ An initially individualistic child is converted into a collectivist adult with a probability of $\sigma>0 . \sigma$ might manifest itself in the form of religious propaganda or patriotic indoctrination from the elite. In the early agricultural states, such an in-group, conformist cultural influence was often intense.

However, also collectivists are subject to a competing, out-group cultural influence. The probability that a collectivist child becomes an individualistic adult is given by $\mu>0$. Such a cultural influence is the result of cultural diffusion from more egalitarian huntergatherer neighboring societies. For the founding agricultural core regions, this influence was most likely weak. We assume initially that $\sigma>\mu$ and that the combined cultural impacts are $\sigma+\mu<1$.

The cultural influences described above imply that the share of the population that is individualistic in period $t+1$, given a level $\omega_{t}>0$ in period $t$, is

$$
\omega_{t+1}=\omega_{t}(1-\sigma)+\left(1-\omega_{t}\right) \mu=P_{t}^{I}\left(\omega_{t}, \sigma, \mu\right)
$$

The proportional share of the individualistic population $\omega_{t+1}$ is equal to the probability at $t$ that any child turns out to be individualistic at $t+1 ; P_{t}^{I}\left(\omega_{t}, \sigma, \mu\right)$.

Comparative statics on the basis of (5) reveals that

$$
\begin{aligned}
& \frac{\partial P_{t}^{I}}{\partial \omega_{t}}=1-\sigma-\mu>0 \\
& \frac{\partial P_{t}^{I}}{\partial \sigma}=-\omega_{t}<0 ; \quad \frac{\partial P_{t}^{I}}{\partial \mu}=\left(1-\omega_{t}\right)>0
\end{aligned}
$$

In other words, the probability that any grown-up child will be an individualist in adulthood will thus increase with the fraction in the population that are already individualist $\omega_{t}$ and with the strength of outside influences $\mu$, whereas the probability decreases with the strength of cultural assimilation $\sigma$.

\footnotetext{
${ }^{13}$ One might have modelled the cultural influence on children as having first a parental influence stage, then an influence from society at large (see for instance the appendix in Ashraf and Galor, 2011b). Since the qualitative insights would have been the same, we refrain from including such a parental stage.
} 
The equivalent probability that any child will be a collectivist in adulthood is

$$
1-\omega_{t+1}=\omega_{t} \sigma+\left(1-\omega_{t}\right)(1-\mu)=P_{t}^{C}\left(\omega_{t}, \sigma, \mu\right) .
$$

Given the structure of the parameters, it will be the case that $P_{t}^{I}<P_{t}^{C}$ at all $t .{ }^{14}$

\subsubsection{Steady states}

Based on the results above, the indirect utility of an individual of type $i \in\{I, C\}$ at some time $t$ can be expressed as

$$
\begin{aligned}
v_{t}^{i} & =\left(w_{t}-\tau n_{t}^{*}\right)^{\gamma} \cdot\left(P_{t}^{i} n_{t}^{*}\right)^{1-\gamma}=\left(\gamma w_{t}^{*}\right)^{\gamma} \cdot\left(\frac{P_{t}^{i}(1-\gamma) w_{t}^{*}}{\tau}\right)^{1-\gamma}= \\
& =\gamma^{\gamma}\left(\frac{A}{L_{t}}\right)^{1-\alpha}\left(\frac{\tau}{1-\gamma}\right)^{\gamma-1}\left(P_{t}^{i}\right)^{1-\gamma}
\end{aligned}
$$

Over time, a gradual increase in the level of the population $L_{t}$ will push wages and income per capita levels down due to diminishing returns to labor and result in a lower welfare. This process will continue until the economy has converged to a steady state.

Note also that the fact that $P_{t}^{I}<P_{t}^{C}$ implies that $v_{t}^{I}<v_{t}^{C}$ at all $t$, i.e. individualists are always worse off in the core than the collectivists.

In this Malthusian economy, the size of the population will reach a steady state when $L_{t+1}=L_{t}=\bar{L}$ so that $\bar{n}=1$. Combining (3) and (4), we can deduce that the steady state level of population in the core is

$$
\bar{L}=A \cdot\left(\frac{1-\gamma}{\tau}\right)^{\frac{1}{1-\alpha}}
$$

Total population thus increases with the productivity of land $A$ and decreases with the cost of raising children $\tau$. Inserting this level into (4), we find that the associated steady state wage level (equal to the steady state income per person) is

$$
\bar{w}=\frac{\tau}{1-\gamma}=\bar{y}
$$

This expression shows a fundamental insight from Malthusian models that long-term income per capita is unaffected by land productivity $A$. A better land quality instead results in a higher population, which eventually pushes per capita incomes down to $\bar{y}$.

In a similar way, the steady state proportions of individualists and collectivists in the population can be found to be

$$
\bar{\omega}=\frac{\mu}{\sigma+\mu}=\bar{P}^{I} ; \quad 1-\bar{\omega}=\frac{\sigma}{\sigma+\mu}=\bar{P}^{C} .
$$

\footnotetext{
${ }^{14}$ Comparing the two probabilities shows that $P_{t}^{I}-P_{t}^{C}=2\left(\mu+\omega_{t}(1-\sigma-\mu)-0.5\right)<0$. A formal demonstration that this inequality always holds at the assumed parameter values is available upon request.
} 
$\bar{\omega}$ increases with the strength of outside forces $\mu$ and decreases with internal cultural influence $\sigma$. The reverse is true for the conformist share of the population. It is also easily verified that $\bar{P}^{I}<\bar{P}^{C}$.

\subsection{The colonization decision}

So far, the exposition has been a compact version of the Malthusian model of Ashraf and Galor (2011b). We will now introduce a new aspect not covered by the initial model; a decision for farmers in the core about whether to remain at home or move to a new frontier territory and found an agricultural colony. This colonization of the frontier by farmers from the core thus constitutes the time for the frontier region's transition to agriculture. We assume that in each time period, individuals first consider the choice of staying or leaving and then produce and consume according the standard optimization described above. We will thus have a repeated two-stage process in which individuals take the second stage decisions into account already in the initial migration stage.

In making the first-stage decision, individuals consider three factors; (i) the indirect utility of remaining in the core, (ii) the indirect utility of living and farming in a new area, and (iii) the fixed costs associated with the break-up and colonization of a land inhabited by hunter-gatherers. Since we know from above that individualists in the core always have a lower indirect utility than the collectivists, it is sufficient to focus only on the individualists' choice of whether to stay in their region of origin or to emigrate and colonize some other region. We will assume that the agricultural economy has reached its steady state levels of population $\bar{L}$ and income $\bar{y}$ but that the evolution of cultural types is still going on. Once a migration of individualists from the core has taken place, further migrations from the core are not possible.

\subsubsection{Core-frontier differences}

What affects the individualists' welfare in case of a colonization of a frontier territory? To begin with, we assume that the colonizers would have to bear a fixed costs $\eta+\theta>0$. $\eta$ reflects the often substantial hardships of breaking up and migrating to a new region. $\theta$ are costs of adaptation in the frontier region. These might include the need to adjust the package of plants and animals brought from the core due to new climatic or soil characteristics. The cost of adaptation should also increase with the level of resistance from the local hunter-gatherers.

Second, we assume that land productivity $A_{f}$ is typically lower in the frontier. This is a similar assumption as in Olsson and Hibbs (2005) and the intuition is that the core region is the most productive region for agriculture, which in turn explains why its population made the transition from hunting-gathering first.

Third, as mentioned above, we assume that the core region has reached its steady-state level of total population $\bar{L}$ but not yet its steady-state proportion of individualists $\bar{\omega}$. In case of a migration, the population will be in disequilibrium in both core and frontier and 
population growth will resume.

After colonization, the relative strength of cultural influences would also be different. The colonists who move to the frontier will set up a new society which they will now govern themselves. Also in this frontier, the agricultural mode of production will inevitably require substantial coordinated efforts such as clearing of land, planning and construction of villages, defensive fortifications, planting, sowing and harvesting. In order to cope with these necessary tasks, a central authority needs to make decisions for the community as a whole. Infectious diseases will most likely also take root and the farmers will be attacked by predatory hunter-gatherers. Due to these forces, there will therefore gradually emerge new collectivist tendencies from within the new society to conform, in a similar manner as in the core.

However, since the group of colonists who initially moved to the new territory were all individualistic types, the cultural influences towards collectivism in the frontier are weaker than if the group had stayed in the core. Although all populations probably have some inclinations towards conformism, such predispositions should be a lot less pronounced among marginalized groups who choose to emigrate rather than submitting to an autocratic leadership. We convey this idea by assuming that the collectivistic cultural influence in the new land becomes $\sigma_{f}=\sigma(1-\delta)$ where $\delta<1$. $^{15}$

By the same logic, if all the individualists leave the core region, the forces towards collectivism should become even stronger there after their departure. For simplicity, let us assume that the strength of cultural assimilation after a break-up is $\sigma_{c}=\sigma(1+\delta)$ so that the differences in cultural influences between core and frontier are symmetric. $\mu$ remains constant in both locations.

Finally, let us assume that the choice at time $t-1$ whether to emigrate or not is determined by the criterion in (10), showing the expected net welfare gain from a move to the frontier that is completed at $t$ :

$$
\begin{aligned}
\Omega_{t-1}^{f} & =v_{t}^{I, f}-v_{t-1}^{I}-\eta-\theta= \\
& =\gamma^{\gamma} \bar{y}^{\gamma-1}\left(\frac{A_{f}}{\omega_{t-1} \bar{L}}\right)^{1-\alpha}\left(P_{t}^{I, f}\right)^{1-\gamma}-\gamma^{\gamma} \bar{y}^{\gamma} \cdot\left(P_{t-1}^{I}\right)^{1-\gamma}-\eta-\theta= \\
& =\gamma^{\gamma} \bar{y}^{\gamma}\left[\left(\frac{A_{f}}{\omega_{t-1} A}\right)^{1-\alpha} \cdot\left((1-\sigma(1-\delta))^{1-\gamma}-\left(\omega_{t-1}(1-\sigma)+\left(1-\omega_{t-1}\right) \mu\right)^{1-\gamma}\right]\right. \\
& -\eta-\theta
\end{aligned}
$$

In this expression, the individualists compare the expected indirect utility after a move to the frontier $v_{t}^{I, f}$ with the current period's indirect utility $v_{t-1}^{I}$ and with the costs of

\footnotetext{
${ }^{15}$ One might certainly argue that cultural influences towards autocracy are also affected by other factors. The geographical distance to the conformist core might for instance matter. Ashraf and Galor (2011b) show that the geographical isolation of a region has a strong impact on the extent to which it is exposed to non-conformist ideas. Another well-known hypothesis is that agricultural societies based on irrigation are more prone to develop autocracy than regions depending on river fed agriculture (Bentzen et al, 2013; Wittfogel, 1957).
} 
breaking up and migrating $(\eta+\theta)$. The indirect utility terms depend on utility from income per person and from the proportion of individualistic types in the population. Utility from income in the frontier in the lower line is $\bar{y}^{\gamma} \cdot\left(\frac{A_{f}}{\omega_{t-1} A}\right)^{1-\alpha}$ which is greater than utility from steady-state income in the core $\bar{y}^{\gamma}$ if $A_{f}>\omega_{t-1} A$. Income per person in the frontier is often higher than the steady-state level $\bar{y}$ since a relatively small population $\left(\omega_{t-1} \bar{L}\right)$ migrate and have a relatively high marginal productivity right after the move.

The proportion of individualists one period after a move to the frontier is $P_{t}^{I, f}=$ $\omega_{t+1}^{f}=1-\sigma(1-\delta)$. This follows from the fact that $\omega_{t}^{f}=1$, i.e. in the first period in the new land, the whole migrating population will at first be individualistic, whereupon a fraction $\sigma(1-\delta)$ will turn collectivist already in $t+1$. If the individualists stay in the core, their population share at $t$ would instead have been $P_{t-1}^{I}=\omega_{t}=\omega_{t-1}(1-\sigma-\mu)+\mu$.

The individualists will only decide to move if $\Omega_{t-1}^{f}>0$. The representative individuals in the model are only able to plan for their off-spring one generation ahead and do not take into account the long-term, steady-state consequences of a move. Furthermore, we assume that only one wave of out-migration from each region is possible.

The expression in (10) allows us to express the following result:

Proposition 1: The probability of a break-away and colonization by the individualistic farmers increases with $A_{f} / A, \delta$ and $\tau$ and decreases with $\mu, \eta$ and $\theta$ at any $t$.

The results follow from straightforward comparative statics on the basis of (10). Although we know that $A_{f} / A<1$ is most often the case, a relatively high ratio (indicating small land productivity differences) will make a colonization more likely. The factor capturing the decrease in collectivist influences in the frontier, $\delta$, is also positively related to a decision to migrate. Not surprisingly, the individualists will appreciate if their own cultural type stands a greater chance of maintaining a high proportion in the future.

A high $\mu$ in the core makes a colonization by individualists less likely. The intuition is that a strong individualistic cultural influence from outside the core would balance the evolution of collectivist and individualistic attitudes and make living in the core more tolerable for the individualists.

Should the time cost of raising children $\tau$ be very high, this will make a colonization less likely. If, for instance, both core and frontier are in a very harsh climate, $\tau$ is probably high, which in turn will imply that people choose to have relatively few children. Few children means a relatively low steady-state level of the population and, for a given level of $A$, a relatively high steady-state level of income per person. From (10), we see that this will give a greater weight to the utility comparison on the left-hand side and make a migration more likely.

The impact of $\sigma$ is ambiguous since a high level causes both the utility of moving and of staying to be lower. 


\subsubsection{Barriers to migration}

Proposition 1 shows that a higher cost of breaking up $\eta$ and of adaptation $\theta$ will make an emigration a less attractive alternative. It is well known that the settlement of Europe by farming populations was far from a smooth process. As discussed above, there were at least two temporal discontinuities in the spread of agriculture northwestwards: The rapid advance of the LBK-culture into the loess soils of the Rhineland around 5500 BCE and the final move into the Baltic areas after 4500 BCE. Is our model able to accommodate such rather dramatic patterns of farmer settlement?

Judging from the archaeological evidence, it appears that two features are particularly important for understanding the LBK expansion. First, as suggested by Bellwood (2005) and others, the soil and climate of the Northwestern Europe required an adjusted combination of plants and animals in order to work. Farmers were probably for a long time unwilling or unable to cope with these very high costs of adjustment $\theta$, which explains why the further settlement was delayed for hundreds of years.

Second, when new colonization eventually did take place and farmers settled the plains of northern Germany and France with their modified technology, they were able to exploit a high land quality $A_{f}$. As shown above, the high land quality implied that population growth was initially very rapid, which could explain the spike in number of archaeological sites in Figure 2.

The later expansion into the coastal areas was most likely delayed for other reasons. The relative suitability of these areas for agriculture was not always great, implying a relatively low $A_{f}$, and farmers met a determined resistance from well-fed hunters and fishermen, living off the aquatic resources of the area. This resistance also implied a high adjustment $\operatorname{cost} \theta$ which had a quite different character from the technological problems of the LBK farmers. The relatively low $A_{f}$ implied that population growth did not take off to the same extent as during LBK. This also explains why we do not see a clear peak for this expansion in Figure 2.

In the empirical section, we will pay special attention to the LBK expansion and investigate whether it was the case that the process of cultural diffusion fundamentally changed after this period.

\subsubsection{Cultural dynamics}

Figure 3 shows a stylized example of the type of long-run cultural dynamics that our model predicts before and after a colonization. Initially, the distribution of cultural types $\omega_{t}$ and $1-\omega_{t}$ is relatively even in the core but the fact that $\sigma>\mu$ inevitably leads to a stronger and stronger domination by the collectivist share of the population. At time $t=-1$, we assume that $\omega_{t}$ has fallen so low that the indirect utility comparison shows that the individualists would actually be better off in the frontier in the next generation. Hence, since the criteria for a migration is fulfilled, they decide to emigrate to the new territory. 


\section{Insert Figure 2}

Immediately after colonization, which happens in a time period that we will refer to as $t=0$, the population in the core will consist of 100 percent collectivists $\left(1-\omega_{0}^{c}=1\right)$ since all the individualists have moved to the frontier. Similarly, the share of collectivists in the frontier will be $1-\omega_{0}^{f}=0$. The emigrated individualists produce, consume, and raise children in their new land. The much lower population in both regions means that wages, birth rates, and utility are initially higher than before.

As new generations grow up, the two regions will be subject to a similar basic process of cultural dynamics as before. Already at $t=1$, the share of individualists in the core will have increased to be $\omega_{1}^{f}=0 \cdot(1-\sigma(1+\delta))+1 \cdot \mu=\mu>0$. In the example in figure 3 , this amounts to $\omega_{1}=0.1{ }^{16}$ The share of collectivists in the frontier in period $t=1$ will be $1-\omega_{1}^{f}=0.2$. The proportion of cultural types in core and colony will immediately start to converge towards their long-run steady state levels. In the example, assuming $\delta=0.5$, the new steady-state ratio of collectivists to individualists will be $\frac{1-\bar{\omega}^{c}}{\bar{\omega}^{c}}=\frac{\sigma(1+\delta)}{\mu}=6$ in the core, compared to 4 before the break-away. Already by three generations after the break-away, the core region will almost have converged, as shown in figure 3 .

In the new land, the proportion of collectivists will rapidly increase as a new community with chiefs and public goods is created. In the example in figure 3 , the collectivists will be in majority already after four generations. The long-run steady state level is even $\frac{1-\bar{\omega}^{f}}{\bar{\omega}^{f}}=\frac{\sigma(1-\delta)}{\mu}=2$ in the colony. Thus, the collectivists will be twice as many as the individualists in the long run. This is certainly a substantially lower ratio than in the core but much higher than in the first pioneer days of the colony.

\subsubsection{Repeated migrations towards periphery}

In the highly stylized example above, there is only a core and a frontier. If we instead imagine multiple regions $\left\{f_{0}(=c), f_{1}, f_{2}, \ldots f_{p}\right\}$, located such that $f_{p}$ is the periphery with the greatest distance to the core, then we can model the further migration of farmers from the first agricultural colony through a whole sequence of migrations towards the periphery. Following the same logic as above, when unhappy individualists decide to leave the first frontier colony $f_{1}$, the collectivist cultural influence will once again increase with a fraction $\delta$ such that $\sigma_{f_{1}}=\sigma(1-\delta)(1+\delta)=\sigma\left(1-\delta^{2}\right)$. In the new colony, we have $\sigma_{f_{2}}=\sigma(1-\delta)^{2}$ to start with and $\sigma_{f_{2}}=\sigma(1-\delta)^{2}(1+\delta)$ after another group of individualists have left $f_{2}$. When farmers have come all the way to the periphery where no further migrations are possible, $\sigma_{f_{p}}=\sigma(1-\delta)^{p}$.

In general, for regions $f_{j}$ where $j \in\{0,1,2, \ldots p-1\}$ are integers, we will have that $\sigma_{f_{j}}=\sigma(1-\delta)^{j}(1+\delta)$. Hence, it is obviously the case that $\sigma_{c}>\sigma_{f_{1}}>\sigma_{f_{2}}>\ldots>\sigma_{f_{p}}$. The steady-state ratio of collectivists to individualists will thus be

\footnotetext{
${ }^{16}$ The example assumes parameter values $\sigma=0.4, \eta=0.1$, and $\delta=0.5$.
} 


$$
\frac{1-\bar{\omega}^{f_{j}}}{\bar{\omega}^{f_{j}}}=\frac{\frac{\sigma_{f_{j}}}{\sigma_{f_{j}}+\mu}}{\frac{\mu}{\sigma_{f_{j}}+\mu}}=\frac{\sigma(1-\delta)^{j}(1+\delta)}{\mu} \text { for all } j \in\{0,1,2, \ldots p-1\}
$$

which falls with $j$. In other words, the periphery will have the greatest proportion of individualists of all regions on the continent due to the repeated process of self-selected migrations by individualists.

\subsubsection{Culture and the time of agricultural transition}

Although we have not explicitly modelled the time since the first introduction of agriculture by migrating farmers into a region, it is very easy to grasp that if $t_{c}$ is the time of introduction of agriculture in the core and $t_{f_{j}}$ is time of colonization of region $f_{j}$, then we will have that $t_{c}<t_{f_{1}}<t_{f_{2}}<\ldots<t_{f_{p}}$. If our contemporary period is $T$, then time since agricultural transition for region $f_{j}$ is $T-t_{f_{j}}$. Since we know that $t_{f_{j}}$ has a negative association with $\sigma_{f_{j}}$ and thus a positive association with $\bar{\omega}^{f_{j}}$, is must be the case that $\bar{\omega}^{f_{j}}$ has a negative relationship with $T-t_{f_{j}}$.

This pattern is the mechanism behind the key hypotheses in the empirical section:

Proposition 2: The steady-state proportion of individualistic cultural norms in a region is negatively related to the time since its settlement by Neolithic farmers.

This proposition summarizes the main insight of the model. To repeat, we have modelled a world where agriculture originates in a core region that is dominated by collectivists. Since the individualists in the core are a shrinking minority, they will eventually find that migrating to the frontier is a better option for the adult generation than remaining at home. ${ }^{17}$ This process then repeats itself as the share of collectivists increases in every frontier region soon after colonization. Agriculture emerges last in the periphery but individualistic norms will be the strongest here due to the repeated self-selection of individualistic migrants. Hence, there is a negative relationship between time since transition to agriculture and the prominence of individualistic norms.

In the empirical sections below, we test the prediction that collectivist cultural norms favoring obedience and autocracy over individualism and democracy, should be stronger in regions that made an early transition to agriculture than in regions that made a later transition.

\section{Data}

The key empirical relationship that we investigate in the sections below is the impact of the time since transition to agriculture on current and historical cultural norms and institutions. In order to measure the timing of the transition to agriculture, we employ the

\footnotetext{
${ }^{17}$ Even during historical episodes when individuals have not self-selected into emigrating, it has very often been marginalized groups who have been forced out of a home country, such as Jewish populations in Medieval Europe or the sentencing of British prisoners to labor in Australia.
} 
same data as in Olsson and Paik (2013). In short, Olsson and Paik (2013) use information from 765 Neolithic sites with calibrated C14-dates of transition throughout Europe and Southwest Asia from Pinhasi et al (2005) to create an approximate date of transition to agriculture for 492 small regions and 64 countries. ${ }^{18}$

The broad area that we study is the Western agricultural core area, encompassing Europe, Southwest Asia, and North Africa. The choice of aggregating these regions follows Morris (2010) and is based on the notion that all these regions experienced a spread of Neolithic agriculture based on domesticated plants and animals from the Fertile Crescent in the Middle East. In the regional sample, we follow Eurostat's definition of European regions on the basis of administrative criteria. Appendix 1 gives information on the divisions of subnational regions: there are 492 regions from 43 countries included in the analysis on norms and 64 Western countries when democracy is the dependent variable. Categories of regions mainly follow Eurostat's definition of European regions on the basis of administrative criteria. At the most aggregated level, NUTS1 level classifies regions with population ranging from 3 to 7 millions; NUTS 2 level divides regions based on population ranging from 800,000 to 3 millions, and NUTS 3 refers to the most disaggregated level- 800,000 and below. For the countries not covered by Eurostat (Iran, Iraq, Jordan, Russian Federation, Saudi Arabia), the intrastate administrative divisions are based on ESRI Data and Maps Series 2006.

The key explanatory variable is Average time since agricultural transition. The mean date of transition (in k years) in the cross-country sample of 43 countries is 7.465 (i.e. 5465 $\mathrm{BCE})$ and $7.28(5280 \mathrm{BCE})$ in the regional sample. Out of these regions, 76 percent of them witnessed adoption after $5500 \mathrm{BCE}$, confirming a rapid dispersion of migrant farmers after LBK expansion. ${ }^{19}$ The earliest transition date in the two samples is from the region Umara in current Iraq where a transition was made already in 8862 BCE.

We use two dependent variables capturing collectivist cultural norms; obedience and control, both obtained from the World Value Survey's four-wave integrated data file between 1981-2004 (WVS, 2006). Both variables have previously featured as key cultural variables in for instance (Tabellini, 2010). We use intrastate regional data at the most disaggregated levels available as the basic unit of analysis, and compare our findings to the aggregate country-level results. While the survey does not specify the hometown of each respondent, it does indicate where the survey took place (Question 048). This information is then used to identify which particular region the respondent lives in. By geographically matching cultural differences among the intrastate regions with the regions' dates of transition to agriculture, we analyze the impact of the Neolithic revolution on the current cultural divergence.

More specifically, WVS provides a list of qualities that children can be encouraged to learn at home, and asks the respondent to choose up to five qualities that are especially

\footnotetext{
${ }^{18}$ See Olsson and Paik (2013) for more detailed information concerning the underlying GIS methodology for mapping the dates from Pinhasi et al (2005) onto geographical units.

${ }^{19}$ Figure 1 shows the distribution of this variable in detail.
} 
important. The level of obedience is measured by aggregating at the regional or country level individual responses which included obedience as an important quality (question A042). It is defined as the percentage of respondents in each geographical unit that has mentioned obedience as being important.

Similarly, control measures the degree that the individual experiences a freedom of choice and a sense of control of one's life. The information comes from question A173 in the survey: "Some people feel they have completely free choice and control over their lives, while other people feel that what we do has no real effect on what happens to them. Please use this scale (from 1 to 10) where 1 means "none at all" and 10 means "a great deal" to indicate how much freedom of choice and control in life you have over the way your life turns out." Tabellini (2010) interprets a high score on this variable as reflecting a belief that individual effort is likely to pay off. Figures 3 and 4 present regional scatter plots of the obedience and control measures against the agricultural adoption date, respectively, in a sample of almost 500 regions. The value for obedience is positively correlated, while the feeling of control is negatively correlated with the time since agriculture. What also appears very clearly in the graphs is a cluster of observations from the LBK expansion that started to emerge about 7500 years ago.

\section{Insert Fig 3 \\ Insert Fig 4}

Apart from the obvious advantage of using variables that have been often used in other studies, how do we motivate our use of these two particular indicators as proxies for conformist cultural norms? Starting with obedience, we interpret this norm to be strongly salient in both primitive and modern hierarchical, collectivist societies, indicating the level of acceptance in a hierarchical system. It is also closely related to the IndividualismCollectivism (I-C) cultural construct, which has been the focus of many studies in a wide range of disciplines (Triandis, 1987; Kitayama et al, 2007). Individualism has been defined as "the subordination of the goals of the collectivists to individual goals, whereas collectivism involves the opposite, that is, the subordination of the individual to the goals of a collective (Hui and Triandis, 1986). Individualists perceive themselves as independent of collectives; give priority to their own preferences, needs, and rights; are motivated to achieve personal goals rather than the goals of others (Hui and Triandis, 1986); are driven by their own beliefs, values and attitudes (Leung and Bond, 1984); and focus on rational analyses of the advantages and disadvantages of establishing contacts with others. On the other hand, collectivist societies consist of closely linked individuals who see themselves as parts of one or more collectives, and hence, are more likely to be driven by social norms, obligations and duties imposed by those collectives. ${ }^{20}$

\footnotetext{
${ }^{20}$ As an example that classifies farmers as collectivists, Keeley (1988) conducts a study of 94 existing primitive groups, and finds positive correlations among class division, storage of resources and level of sedantism. Triandis (1987) finds that individualist societies tend to be hunting, gathering, fishing, or foraging societies. The members of these societies do much trading and prod children to become adults,
} 
The measures for obedience and control are exceptions to other cultural measures discussed in numerous studies, in the sense that the others are not more easily categorized along the I-C cultural construct. For example, the very often used indicator for generalized trust is a variable that is not easily identified along the $\mathrm{I}-\mathrm{C}$ construct. ${ }^{21} \mathrm{It}$ is created from responses to the following question (A165): "Generally speaking, would you say that most people can be trusted or that you can't be too careful in dealing with people?" The question does not clarify how each respondent defines "most people" in the survey. People can be inclusive of aliens outside the respondent's country, or only the ones within the respondent's home region. If it pertains only to close acquaintances, the response would be very different as well. Similarly, most of the qualities in children mentioned above are universally accepted as important to society regardless of its cultural construct: hard work, perseverance, unselfishness and thriftiness are qualities that would have been valued in both prehistoric and modern societies.

There are of course geographic factors and historical events that may also have influence on the current variations of beliefs in obedience and sense of control. These include the mean elevation, access to water and area coverage, as well as empires that encompassed many of the regions, intensification of agriculture and the Industrial Revolution. To see why empires matter, note that the roots of European growth is commonly seen in the Roman Empire (Jones, 1981), while the presence of Ottoman rule may have eradicated some nations' Roman traditions (Acemoglu et al., 2005). This paper includes the approximate number of centuries that each of the Roman, Byzantine and Ottoman empires influenced a region, based on the boundary changes every century from 0 to 2000 AD in Euratlas vectorial maps (http://www.euratlas.com/index.html). Furthermore, the agricultural environment likely had an impact on both early and modern institutions. Our empirical analysis includes the fraction of each land unit cultivated into croplands or pastures in 1600 CE from Pongratz et al. (2008) $)^{22}$ Third, the paper uses the total regional railroad length as a measure of the extent to which each region became industrialized. The railroad was the "perfect symbol of the aspect of continuous, self-sustaining economic growth" of the Revolution (Spielvogel, 1991); as state societies became predominantly urban and state power was based on possession of coal and iron and their production rather

while collectivist societies, tend to be agricultural, only trade minimally, and allow children to become adults when they are ready. Barry et al. (1959) find similar results; in their study, groups categorized as fishing and hunting societies with little accumulation of food resources (as opposed to pastoral/animal husbandry) encourage childraising qualities of achievement and independence, rather than obedience and responsibility. Furthermore, the size of permanent settlement, degree of political integration and social stratification are all positively correlated with pressure towards compliance and the level of resource accumulation. These studies all show that under the I-C cultural construct, there is a close connection between today's primitive group characteristics and archaeological findings, suggesting that there may be persistent cultural inheritance over generations that are evident in modern societies as well.

${ }^{21}$ See for instance Knack and Keefer (1997) for studies of the macro relationship between trust and economic growth.

${ }^{22}$ The year 1600 represents the final period in history when agriculture was the main determinant of living standards and state power. By 1700 overseas trading especially by the Atlantic traders took over, leading the nations to urbanization, increased militarization and pushed them toward the Industrial Revolution (Acemoglu et al., 2005). 
than agriculture, the demand for faster means of transportation to fuel the growth of the industrial economy led to more production of iron and coal, which in turn reinforced the need for expansion of railroads. ${ }^{23}$ Finally, the cultural norms are to a large extent determined by current demography divided according to age, sex and education levels. Age, sex and education levels are directly obtained from WVS. In order to account for these other channels through which cultural divergence may have risen, this paper compares the effect of settlement timing with and without a set of these controls. The main results, as will be shown below, remain robust to these controls.

\section{$5 \quad$ Empirical Strategy}

As discussed above, our empirical analysis investigates the relationship between our dependent variables cultural norms/institutions and our main independent variable Average time since the transition to agriculture on two levels of aggregation: Western countries and Western regions. First in the cross-country analysis, our straightforward specification is

$$
Z_{i}=\alpha_{1}+\alpha_{2} T_{i}+\alpha_{3} X_{i}+\epsilon_{i}
$$

where $Z_{i}$ is our measure of cultural norms (obedience or control) or democratic institutions in country $i, T_{i}$ is the Average time since the transition to agriculture, $X_{i}$ is a set of geographic and historical control variables discussed in detail above, and $\epsilon_{i}$ is a normally distributed error term. Our main hypothesis is that $\alpha_{2}>0$ when $Z_{i}$ is obedience and $\alpha_{2}<0$ when $Z_{i}$ is control or a proxy for democracy. ${ }^{24}$

The contemporary outcomes recorded in $Z_{i}$ typically appeared at least five millennia after $T_{i}$ was realized. Nonetheless, it could potentially be the case that Neolithic norms or institutions had an impact on $T_{i}$ and then persisted to influence $Z_{i}$. This conjecture is impossible to rule out, especially when the Neolithic transition is considered to be the greatest social and technological revolution experienced by man before the Industrial revolution. The transition to agriculture was mainly introduced to a region by migrating outsiders. Hence, we believe it is more convincing to argue that outside the region of origin, agriculture appeared as an exogenous intervention that had little to do with huntergatherer institutions at the time. Furthermore, when the Neolithic migrants moved out of the origin of agriculture, they settled in the arable lands with access to water close to the origin, and the timing of agricultural adoption reflects the length of the journey that migrants needed to take away from their homelands. In order to control for any

\footnotetext{
${ }^{23}$ The railroad data comes from two sources; for Europe, the ESRI 2008 Street Map and Data contains the railroad information in ArcGIS format. For the Middle East, the railroad data was obtained from MAPSearch's 2007 Middle East Pipeline/Facilities Spatial and Relational Data.

${ }^{24} \mathrm{~A}$ number of studies have hypothesized that there is either a causal link from culture to institutions or from formal institutions to culture (Alesina and Giuliano, 2014). In this study, our main argument is that both culture and institutions are driven by the deeper historical processes inherent in the Neolithic transition to agriculture.
} 
independent effect that geographic endowment might have had on the current cultural outcomes, we include a group of geographic variables including the area scale, access to water and the mean elevation.

In addition to the list of geographic variables, there is a spike in the spread of agriculture in $5500 \mathrm{BCE}$, as shown in Figure 1. While we cannot accurately control for this distribution pattern at the country level, given the scale of each unit, we are able to account for these events at the regional level. In the regional sample, our specification will therefore be

$$
Z_{i j}=\beta_{1}+\beta_{2} T_{i j}+\beta_{3} X_{i j}+\beta_{4} F_{i}+\epsilon_{i j}
$$

where $Z_{i j}$ now measures cultural norms in region $j$ in country $i$. The main difference from (12) is the inclusion of an indicator in the vector of controls $X_{i}$, for whether the transition took place after $5500 \mathrm{BCE}$, and an interaction term between the indicator and the adoption date variable. We also include the country fixed effect $F_{i}$ so that we can focus on within-country variations.

A potential issue that concerns any works investigating the long term impact of historical events is that the regions in consideration likely were subject to subsequent migrations after the Neolithic Revolution. In this regard, the regions of Europe and the Middle East provide a better ground for empirical testing than others. The Neolithic Revolution in Eurasia was mainly a unidirectional spread of agriculture, with little evidence of people migrating back and forth. Relative to other parts of the world, these regions now consist of almost entirely indigenous populations. Since population admixtures became the norm after the great diaspora started in the fifteenth and sixteenth centuries, especially in the Americas, it is imperative to take further precautions and look at a continent where such admixture is minimized (Spolaore and Wacziarg, 2013). Putterman and Weil (2010) finds that Europe is a continent of countries with almost entirely indigenous populations in contrast to some countries of the New World (Australia, New Zealand and Canada) that are predominantly of European origin, and some others (Central American and Andean countries) that have both large Amerindian and substantial European-descended populations.

\section{Findings}

Tables 1-3 present the results from our regression analysis. ${ }^{25}$ Given that the norms against obedience and emphasis on control in one's life are pronounced in democratic institutions, are countries in fact more likely to be democratic if they adopted agriculture later? Table 1 presents a number of indicators for democracy, both historical (Executive constraint in 1500 AD from Acemoglu et al., 2005) and current (Democracy stock from 1900 to 2000,

\footnotetext{
${ }^{25}$ The estimates for geographical, historical, and demographic control variables are not shown in the tables but are available upon request.
} 
depreciated 1 percent from Gerring et al., 2005), and Polity 2 measured in 2010 against the agricultural adoption date. It also presents the individualism range, one of six dimensions of culture as presented in Hofstede et al (2010). ${ }^{26}$ Regardless of which variable we use, the relationship between our indicators for democracy and individualism, and time since the Neolithic revolution, remains negative and robust. The coefficient values suggest that it was unlikely for countries which adopted agriculture early to have experienced democracy or become individualistic during the last century.

\section{Insert Table 1}

Our main dependent variables are however obedience and control, reflecting cultural norms conducive to individualism as opposed to collectivism. Table 2 presents the empirical results at the country level. The coefficient value of the average adoption date is statistically significant as controls are included in Columns 1 to 3. The Geography controls include the mean elevation, coast to area ratio and area; Historical controls include the fraction of arable land in 1600, the number of centuries of Roman, Byzantine and Ottoman Empire rule, and length of railways; and finally Demography controls include average age, sex ratio and education levels of WVS respondences.

\section{Insert Table 2}

In Column 3, the coefficient value of 9.5 suggests that a country adopting agriculture early by 1000 years is likely to witness an increase of 9.5 in the percentage of respondents valuing obedience. In other words, one standard deviation of agricultural transition explains about 70 percent of the standard deviation in the obedience measure. ${ }^{27}$ Similarly, Columns 4 to 6 present results in which the dependent variable is the control measure. With the exception of Column 5, in which the t-stat for the agricultural adoption measure is -1.52 , there is a strong negative correlation between the level of confidence in the respondent's sense of being in control of his/her life and how early the country adopted agriculture. In Column 6, a delay in agricultural transition by 1000 years explains an increase in the percentage by 9 points.

Table 3 presents the regional analysis with the same set of controls. The main difference here is that unlike the country-level analysis, in which the agricultural adoption date is averaged across the entire country, we are now able to make a more accurate use of the transition dates based on Pinhasi et al (2005)'s detailed data. Apart from the continuous measure of the agricultural adoption date, we now introduce a binary variable based on whether the region experienced its agricultural transition later than $5500 \mathrm{BCE}$, i.e. after the LBK expansion. The analysis also includes the interaction term between the adoption

\footnotetext{
${ }^{26}$ The range is from 0 to 100 , with 100 reflecting the most individualistic country. In our sample the United Kingdom has the highest score of 89, and Pakistan has the lowest score of 14. The other dimensions measured by the authors include power distance, masculinity, uncertainty avoidance, long term orientation and indulgence.

${ }^{27}$ The mean obedience measure is 31 with standard deviation of 14.7, and the mean agricultural adoption date variable is 7.467 with the standard deviation of 1.1
} 
date and the indicator for this time period. Figures 3-4 show the unconditional scatter plots of the relationship between our cultural variables and the agricultural adoption date. In addition to these controls for the LBK expansion, the regression results always include a country-fixed effect.

\section{Insert Table 3}

For both the obedience and control measures, the findings are similar to the ones presented in Table 2; the timing of agricultural transition has a positive impact on the obedience measure and a negative impact on the control measure. The regions on average find that an earlier agricultural adoption by 1000 years is associated with an increase of the percent of respondents valuing obedience by 4.6 to 6.35 points, depending on the regression specification. The effect is similar in magnitude for the decrease in the percent of respondents believing that they have control in their lives. The results are consistent with our main hypothesis proposing that a later transition to agriculture should be associated with stronger norms towards democracy and individualism.

\section{Conclusion}

In this paper, we have outlined an agricultural origins-theory of cultural divergence, arguing that differences in norms along the collectivism-individualism dimension can ultimately be traced back to the Neolithic revolution. Due to the nature of early agricultural production, the high risk of predation from neighbouring peoples, and the high prevalence of infectious disease in the early farming villages, the population in the agricultural core region of Western Eurasia very early developed strong collectivistic cultural norms. Given the threat of extinction in the core, people with individualistic cultural norms chose to migrate and set up farming villages in frontier territories. When collectivistic norms again strengthened also in the new territories, new groups of individualistic migrants pushed the frontier towards the northwest of Europe. In this way, the most individualistic farmers self-selected into eventually occupying the northwestern periphery in Europe in current Great Britain and Scandinavia. This bias in cultural norms towards more individualism in regions that adopted agriculture relatively late, is predicted to have persisted to the present day.

When we confront this hypothesis with data from the World Value Survey on individuals' perceptions of whether children should be obedient and if they have a sense of control of their lives, we find that the strength of individualistic norms is negatively related to the time since the transition to Neolithic agriculture. Likewise, we find that institutions associated with individualism such as the level of democracy are also negatively related to the time since the agricultural transition. In regions where agriculture was adopted early, people do not think they have a strong control of their lives and value obedience and autocracy rather than independence and democracy. 
The model in the paper was primarily designed to explain the gradual expansion of farmers throughout the Western area but might potentially also be used to explain other historical migrations such as the Austronesian expansion in Southeast Asia and in the Pacific and the massive migration of poor Europeans to America during the last two hundred years. Casual observation seems to suggest that it was mainly people with individualistic norms who settled on the other side of the Atlantic. Future research might also shed light on whether the timing of the transition to agriculture is also relevant for understanding related facets of individualism such as the adoption of Protestantism and a preference for social equality. 


\section{References}

[1] Abramitzky, R., L. Boustan, K. Eriksson (2012) "Europe's Tired, Huddled Masses: SelfSelection and Economic Outcomes in the Age of Mass Migration" American Economic Review 102(5), 1832-1856.

[2] Acemoglu, D. et al (2005) "The Rise of Europe: Atlantic Trade, Institutional Change, and Economic Growth" American Economic Review 95(3), 546-597.

[3] Acemoglu, D. and J. Robinson (2012) Why Nations Fail: The Origins of Power, Prosperity and Poverty, New York: Crown Publishers.

[4] Ahlerup, P. and O. Olsson (2012) "The Roots of Ethnic Diversity" Journal of Economic Growth 17(2), 71-102.

[5] Alesina, A. and P. Giuliano (2014) "Culture and Institutions" mimeo, Harvard University.

[6] Ammerman, A. and L. Cavalli-Sforza (1984) The Neolithic Transition and the Genetics of Populations in Europe, Princeton University Press.

[7] Ashraf, Q. and O. Galor (2011a) "Dynamics and Stagnation in the Malthusian Epoch" American Economic Review 101(5), 2003-2041.

[8] Ashraf, Q. and O. Galor (2011b) "Cultural Diversity, Geographical Isolation, and the Origin of the Wealth of Nations" NBER Working Paper 17640.

[9] Ashraf, Q. and O. Galor (2013) "The 'Out of Africa' Hypothesis, Human Genetic Diversity, and Comparative Economic Development" American Economic Review 103(1), 1-46.

[10] Ashraf, Q. and S. Michalopoulos (2011) "The Climatic Origins of the Neolithic Revolution: Theory and Evidence" working paper.

[11] Banfield, E.C. (1958) The Moral Basis of a Backward Society. New York: Glencol.

[12] Barry, H.I., I. Child and M. Bacon (2013) "Relations of Child Training to Subsistence Economy" American Anthropologist 61, 51-63.

[13] Becker, A., T. Dohmen, B. Enke, A. Falk (2014) "The Ancient Origins of the Cross-Country Heterogeneity in Risk Preferences" mimeo.

[14] Bellwood, P. (2005) First Farmers: The Origins of Agricultural Societies, Oxford: Blackwell Publishers.

[15] Bentzen, J.S., N. Kaarsen, and A.M. Wingender (2013) "Irrigation and Autocracy" University of Copenhagen, working paper.

[16] Bisin, A. and T. Verdier (2001) "The Economics of Cultural Transmission and the Dynamics of Preferences" Journal of Economic Theory 97, 298-319.

[17] Blaydes, L. and E. Chaney (2013) "The Feudal Revolution and Europe's Rise: Political Divergence of the Christian and Muslim Worlds before 1500 CE", American Political Science Review (February), 1-19.

[18] Boyd, R. and P. J. Richerson (1985) Culture and the Evolutionary Process. Chicago: University of Chicago Press

[19] Carneiro, R. (1970) "A Theory of the Origin of the State" Science 169, 733-738.

[20] Cavalli-Sforza, L., Menozzi, P. \& Piazza, A. (1994). The History and Geography of Human Genes. Princeton, NJ: The Princeton University Press.

[21] Chikhi, L., Nichols, R. A., Barbujani, G. \& Beaumont, M. A. (2002). "Y Genetic Data Support the Neolithic Demic Diffusion Model", PNAS 99(17351). 
[22] Comin, D., W. Easterly, and E. Gong (2010) "Was the Wealth of Nations Determined in 1000 BCE?" American Economic Journal: Macroeconomics, 2(July), 65-97.

[23] Diamond, J. (1997) Guns, Germs and Steel: The Fates of Human Societies. New York: Norton.

[24] Diamond, J. (2005) Collapse: How Societies Choose to Fail or Succeed. New York: Penguin Group

[25] Eurostat (2012) http://epp.eurostat.ec.europa.eu

[26] Fincher, C.L., R. Thornhill, D.R. Murray, and M. Schaller (2008) "Pathogen Prevalence Predicts Human Cross-Cultural Variability in Individualism/Collectivism" Proceedings of the Royal Society B, 275, 1279-1285.

[27] Gerring, J., P. Bond, W. Barndt, and C. Moreno (2005) "Democracy and Economic Growth: A Historical Perspective", World Politics 57(April), 323-364.

[28] Greif, A. (2006) Institutions and the Path to the Modern Economy, Cambridge University Press.

[29] Gorodnichenko, Y. and G. Roland (2010) "Culture, Institutions and the Wealth of Nations" NBER Working Paper 16368.

[30] Gorodnichenko, Y. and G. Roland (2011) "Which Dimensions of Culture Matter for LongRun Growth?" American Economic Review: Papers and Proceedings 101(3), 492-498.

[31] Gorodnichenko, Y. and G. Roland (2013) "Culture, Institutions and Democratization" mimeo.

[32] Hansen, C.W., P.S. Jensen, C. Skovsgaard (2013) "Modern gender Roles and Agricultural History: The Neolithic Inheritance" University of Southern Denmark, working paper.

[33] Hofstede G., Hofstede G.J. and Minkov M. (2010) Cultures and organizations: software of the mind: intercultural cooperation and its importance for survival, 3rd ed.. New York: McGraw Hill.

[34] Hui, C.H. and H.C. Triandis (1986) Individualism-Collectivism: A Study of Cross-Cultural Perspectives. Lincoln: Nebraska University Press.

[35] Jones, E.L. (1981) The European Miracle: Environments, Economies and Geopolitics in the History of Europe and Asia. Cambridge: Cambridge University Press.

[36] Keeley, L.W. (1988) "Hunter-gatherer Economic Complexity and "Population Pressure": a Cross-cultural Analysis" Journal of Anthropological Archaeology 7, 373-411.

[37] Kitayama, S., S. Duffy and Y. Uchida (2007) Self as Cultural Mode of Being, in S. Kitayama and D. Cohen (eds), Handbook of Cultural Psychology. New York: The Guiford Press.

[38] Knack, S.F. and P. Keefer (1997) "Does Social Capital Have an Economic Payoff? A CrossCountry Investigation" Quarterly Journal of economics, 112(2), 1251-1288.

[39] Lagerlöf, N.P. (2013) "Statehood, Democracy, and Preindustrial Development" working paper.

[40] Leung, K. and M.H. Bond (1984) "The Impact of Cultural Collectivism on Reward Allocation" Personality and Social Psychology 47, 793-804.

[41] Litina, A. (2013) "Unfavorable land endowment, cooperation, and reversal of fortune" MPRA Paper No. 39702.

[42] Leung, K. and M. H. Bond (1984) "The Impact of Cultural Collectivism on Reward Allocation" Personality and Social Psychology, 47, 793-804. 
[43] Morris, I. (2010) Why the West Rules - For Now: The Patterns of History and What They Reveal About the Future, London: Profile Books.

[44] North, D. and R.P. Thomas (1973) The Rise of the Western World: A New Economic History. New York: Cambridge University Press.

[45] North, D. (1990) Institutions, Institutional Change and Economic Performance. Cambridge University Press.

[46] Olsson, O. and Hibbs, D.A. (2005) "Biogeography and Long-Run Economic Development" European Economic Review 49(4), 909-938.

[47] Olsson, O. and C. Paik (2013) "A Western Reversal Since the Neolithic? The Long-Run Impact of Early Agriculture" working paper.

[48] Pinhasi, R., J. Fort, and A. Ammerman (2005) "Tracing the Origins and Spread of Agriculture in Europe" PLOS Biology 3(12), 2220-2228.

[49] Pomeranz, K. (2000) The Great Divergence: China, Europe, and the Making of the Modern World Economy. Princeton: Princeton University Press.

[50] Pongratz, J., C. Reick, T. Raddatz, and M. Claussen (2008) "A reconstruction of global agricultural areas and land cover for the last millennium" Global Biogeochem. Cycles 22.

[51] Postgate, J.N. (1995) Early Mesopotamia: Society and Economy at the Dawn of History. London: Routledge

[52] Putnam, R. (1993) Making Democracy Work: Civic Traditions in Modern Italy. Princeton: Princeton University Press.

[53] Putterman, L. (2008) "Agriculture, Diffusion and Development: Ripple Effects of the Neolithic Revolution" Economica 75(300): 729-748.

[54] Putterman, L. and D. Weil (2010) "Post-1500 Population Flows and the Long-Run Determinants of Economic Growth and Inequality" Quarterly Journal of Economics 125(4), 1627-1682.

[55] Spielvogel, Jackson J. (1991). Western Civilization: A Brief History, West Publishing Company.

[56] Wittfogel, K. (1957) Oriental Despotism: A Comparative Study of Total Power. New Haven: Yale University Press.

[57] Spolaore, E. and R. Wacziarg (2013) "How Deep are the Roots of Economic Development?" Journal of Economic Literature 51(2), 1-45.

[58] Talhelm, T. et al (2014) "Large-Scale Psychological Differences Within China Explained by Rice Versus Wheat Agriculture" Science 344 (9 May), 603-608.

[59] Tabellini, G. (2010) "Culture and Institutions: Economic Development in the Regions of Europe" Journal of the European Economic Association, 8(4), 677-716.

[60] Thornhill, R., C.L. Fincher and D. Aran (2009) "Parasites, Democratization, and the Liberalization of Values Across Contemporary Countries" Biological Reviews 84, 113-131.

[61] Thornhill, R. and C. Fincher (2013) The Parasite-Stress Theory of Values and Sociality, New York: Springer.

[62] Triandis, H.C. (1987)Cross-cultural Studies of Individualism and Collectivism, in J.J. Berman (ed.), Cross-Cultural Perspective, Lincoln: University of Nebraska Press.

[63] Wittfogel, K. (1957) Oriental Despotism: A Comparative Study of Total Power. New Haven: Yale University Press. 
Tables 


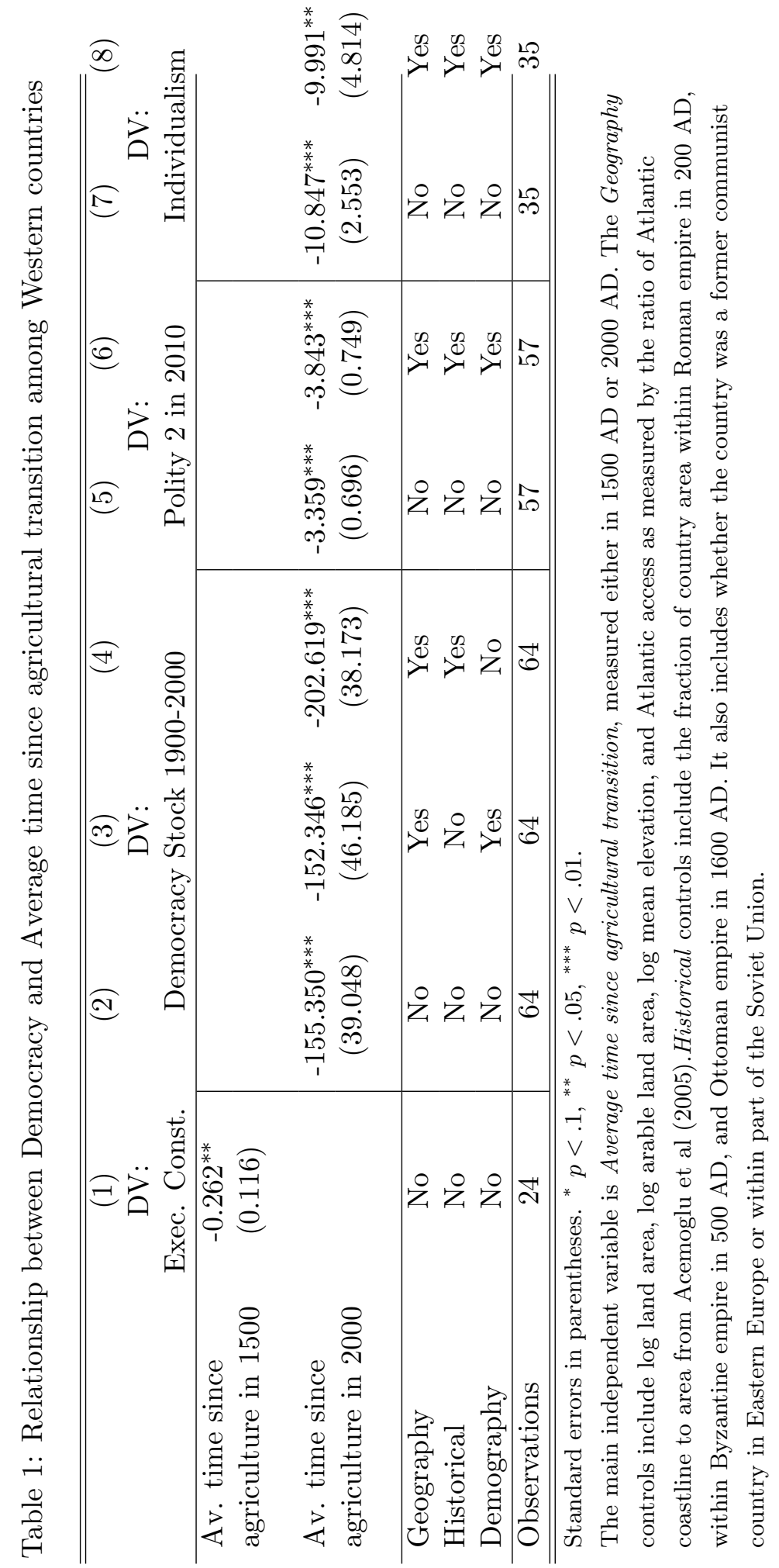


Table 2: Relationship between cultural dependent variables Obedience and Control and independent variable Average time since agricultural transition among 43 Western countries

\begin{tabular}{lccc|ccc}
\hline \hline & $(1)$ & $\begin{array}{c}(2) \\
\text { DV:Obedience }\end{array}$ & $(3)$ & $(4)$ & $\begin{array}{c}(5) \\
\text { DV:Control }\end{array}$ \\
& \multicolumn{3}{c}{ DV } & \\
Av. time since & $7.998^{* *}$ & $10.317^{* * *}$ & $9.508^{* *}$ & $-7.763^{* *}$ & -4.187 & $-8.992^{*}$ \\
agriculture in 2000 & $(3.157)$ & $(3.518)$ & $(4.623)$ & $(3.769)$ & $(2.750)$ & $(4.801)$ \\
\hline Geography & Yes & Yes & Yes & Yes & Yes & Yes \\
Historical & No & Yes & Yes & No & Yes & Yes \\
Demography & No & No & Yes & No & No & Yes \\
\hline Observations & 43 & 42 & 41 & 43 & 42 & 41 \\
\hline \hline
\end{tabular}

Standard errors in parentheses; ${ }^{*} p<.1,{ }^{* *} p<.05,{ }^{* * *} p<.01$.

The main independent variable is Average time since agricultural transition in 2000.

Geography controls include mean elevation, land area and ratio of Atlantic Coast

to area from Acemoglu et al (2005). Historical controls include agricultural suitability in $1600 \mathrm{AD}$ and total railroad length, centuries of rule under Roman, Ottoman and Byzantine empires. Demography controls include the average age, percentage of males and years in school among the WVS respondents. 
Table 3: Relationship between Obedience and Control, and Average time since agricultural transition among 492 Western regions

\begin{tabular}{lccc|ccc}
\hline \hline & $(1)$ & $(2)$ & $(3)$ & $(4)$ & $(5)$ & $(6)$ \\
& \multicolumn{3}{c}{ DV:Obedience } & \multicolumn{3}{c}{ DV:Control } \\
\hline Agric. time since & $4.790^{* *}$ & $6.350^{* * *}$ & $4.610^{* *}$ & $-4.939^{* *}$ & $-6.826^{* * *}$ & $-4.747^{* *}$ \\
agriculture in 2000 & $(2.231)$ & $(2.319)$ & $(2.020)$ & $(2.331)$ & $(2.395)$ & $(2.392)$ \\
\hline Geography & Yes & Yes & Yes & Yes & Yes & Yes \\
LBK Interaction & Yes & Yes & Yes & Yes & Yes & Yes \\
Historical & No & Yes & Yes & No & Yes & Yes \\
Demography & No & No & Yes & No & No & Yes \\
Country F/E & Yes & Yes & Yes & Yes & Yes & Yes \\
\hline Observations & 472 & 466 & 400 & 486 & 481 & 415 \\
\hline \hline
\end{tabular}

Standard errors in parentheses; ${ }^{*} p<.1,{ }^{* *} p<.05,{ }^{* * *} p<.01$.

The main independent variable is Average time since agricultural transition in 2000.

Geography controls include mean elevation, land area and ratio of Atlantic Coast

to area from Acemoglu et al (2005). Historical controls include agricultural suitability

in $1600 \mathrm{AD}$ and total railroad length, centuries of rule under Roman, Ottoman

and Byzantine empires. Demography controls include the average age, percentage of males and years in school among the WVS respondents. All specifications further include country fixed effects, an LBK dummy $(=1)$ if the transition to agriculture happened after $7500 \mathrm{BC}$, and an interaction term between the LBK dummy and Average time since agricultural transition in 2000. 


\section{Figures}

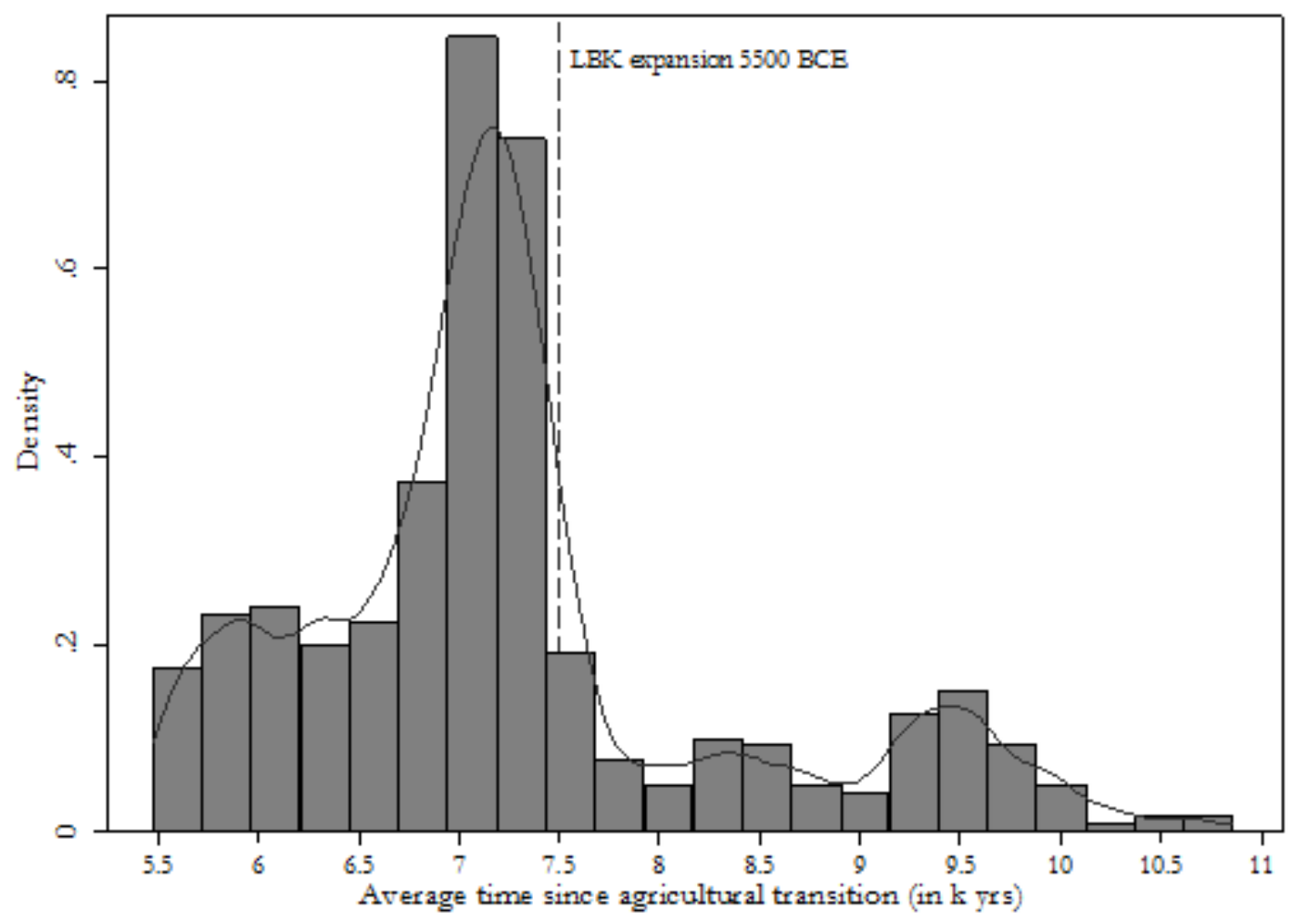

Figure 1: Distribution of average time since agricultural transition over Western 492 regions 


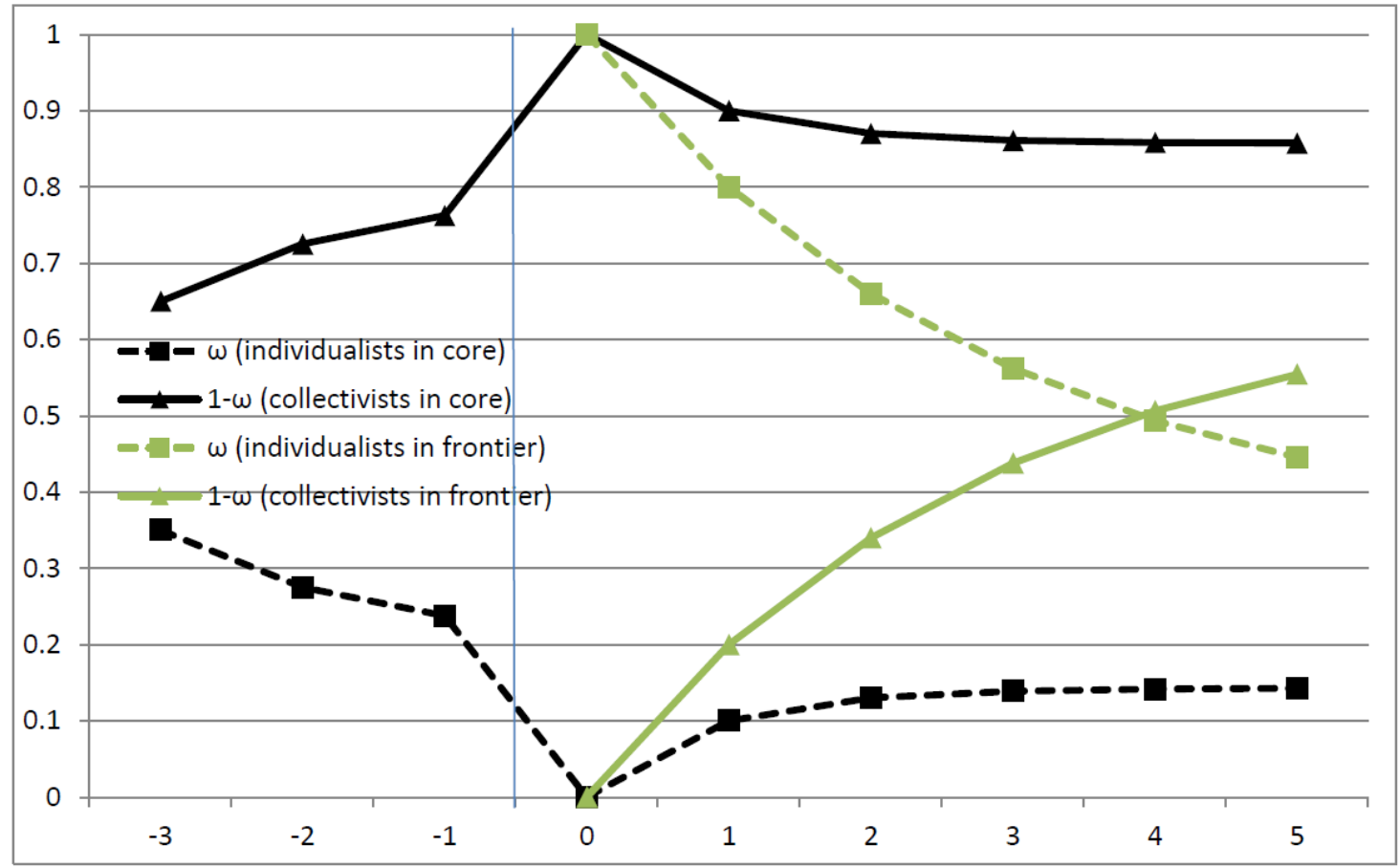

Note: The vertical axis shows proportions of total population and the horizontal axis shows time $t$. Colonization happens at $t=0$. The black lines shows developments in the core before and after colonization whereas the green lines shows developments in the periphery after colonization. The simulations in the figure assumes parameter values $\sigma=0.4, \mu=0.1$, and $\delta=0.5$. Please see text for further explanations.

Figure 2: Example of individualist and collectivist population share dynamics before and after a colonizing event 
Figure 3: Unconditional linear relationship between Obedience and Average time since agricultural transition in Western regions

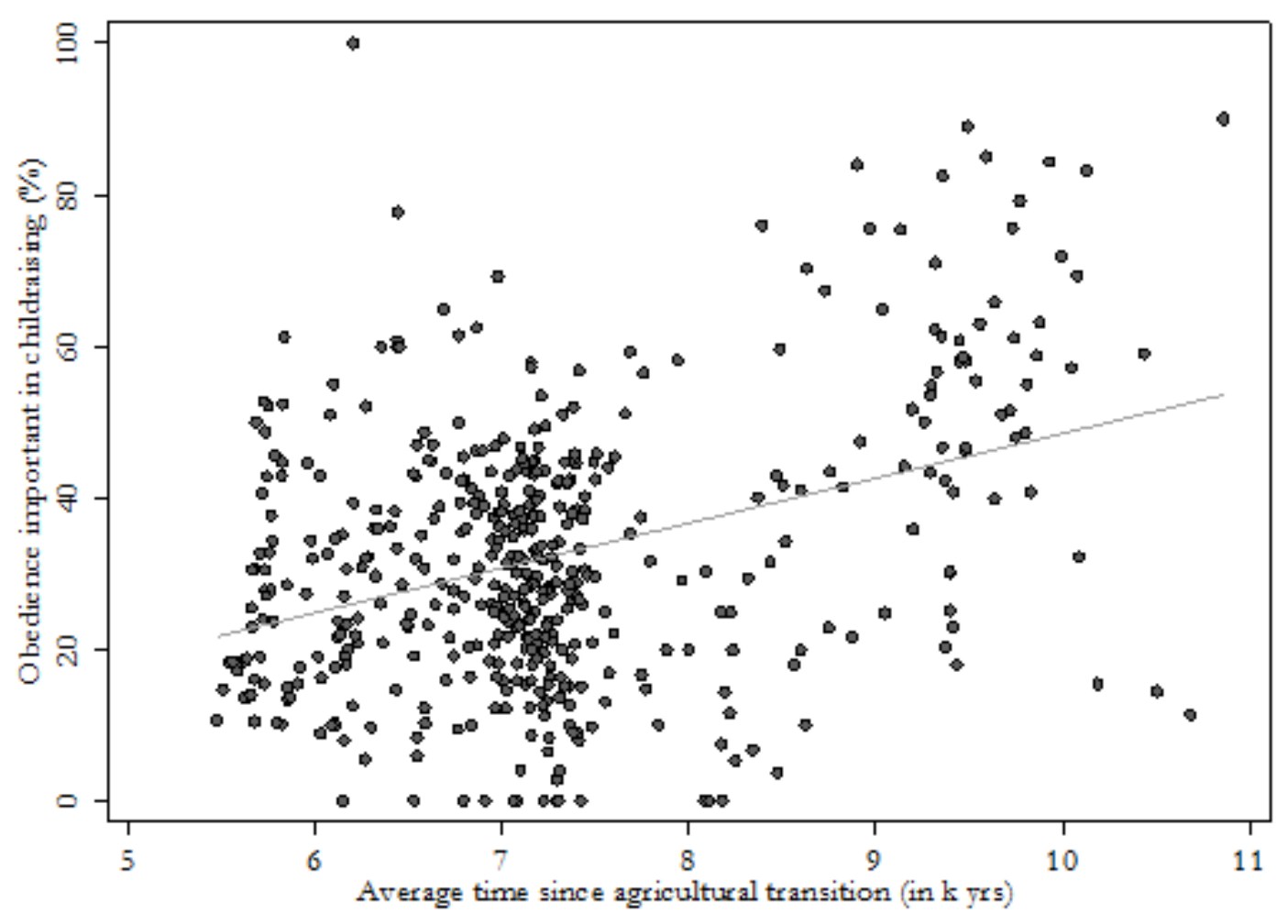

Note: the line slope coefficient estimate is from Table 3 Column 1. 
Figure 4: Unconditional linear relationship between Control and Average time since agricultural transition in Western regions

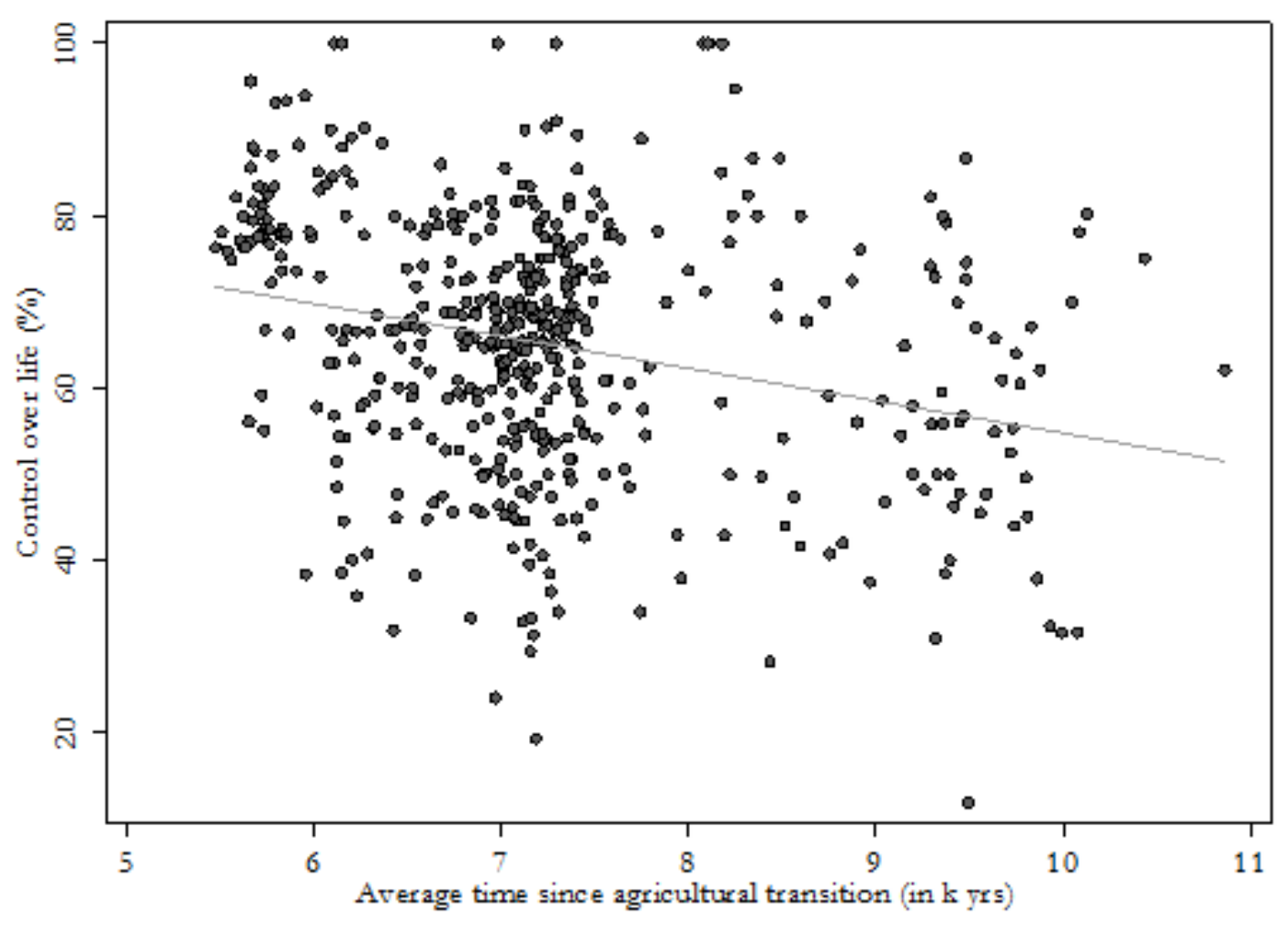

Note: the line slope coefficient estimate is from Table 3 Column 4. 


\section{Appendix}

Table 4: Regional Classification

\begin{tabular}{|c|c|c|c|c|c|}
\hline & $\begin{array}{l}\text { Regions } \\
\text { Included }\end{array}$ & NUTS3 & NUTS2 & NUTS1 & Others \\
\hline Albania & 4 & 4 & 0 & 0 & 0 \\
\hline Armenia & 1 & 1 & 0 & 0 & 0 \\
\hline Austria & 9 & 0 & 9 & 0 & 0 \\
\hline Azerbaijan & 1 & 1 & 0 & 0 & 0 \\
\hline Belarus & 6 & 6 & 0 & 0 & 0 \\
\hline Belgium & 10 & 0 & 10 & 0 & 0 \\
\hline Bosnia And Herzegovina & 2 & 0 & 2 & 0 & 0 \\
\hline Bulgaria & 26 & 26 & 0 & 0 & 0 \\
\hline Croatia & 20 & 20 & 0 & 0 & 0 \\
\hline Czech Republic & 10 & 10 & 0 & 0 & 0 \\
\hline Denmark & 14 & 14 & 0 & 0 & 0 \\
\hline Egypt & 6 & 0 & 0 & 0 & 6 \\
\hline France & 8 & 0 & 0 & 8 & 0 \\
\hline Georgia & 1 & 1 & 0 & 0 & 0 \\
\hline Germany & 27 & 0 & 14 & 13 & 0 \\
\hline Great Britain & 12 & 0 & 0 & 12 & 0 \\
\hline Greece & 20 & 20 & 0 & 0 & 0 \\
\hline Hungary & 20 & 20 & 0 & 0 & 0 \\
\hline Iran & 13 & 0 & 0 & 0 & 13 \\
\hline Iraq & 16 & 0 & 0 & 0 & 16 \\
\hline Ireland & 8 & 8 & 0 & 0 & 0 \\
\hline Israel & 6 & 0 & 0 & 0 & 6 \\
\hline Italy & 20 & 0 & 20 & 0 & 0 \\
\hline Jordan & 7 & 0 & 0 & 0 & 7 \\
\hline Latvia & 5 & 5 & 0 & 0 & 0 \\
\hline Lithuania & 8 & 8 & 0 & 0 & 0 \\
\hline Luxembourg & 1 & 1 & 0 & 0 & 0 \\
\hline Macedonia & 1 & 1 & 0 & 0 & 0 \\
\hline Netherlands & 12 & 0 & 12 & 0 & 0 \\
\hline Poland & 34 & 34 & 0 & 0 & 0 \\
\hline Portugal & 5 & 0 & 5 & 0 & 0 \\
\hline Republic Of Moldova & 1 & 1 & 0 & 0 & 0 \\
\hline Romania & 40 & 40 & 0 & 0 & 0 \\
\hline Russian Federation & 2 & 0 & 0 & 0 & 2 \\
\hline Saudi Arabia & 8 & 0 & 0 & 0 & 8 \\
\hline Serbia And Montenegro & 3 & 3 & 0 & 0 & 0 \\
\hline Slovakia & 8 & 8 & 0 & 0 & 0 \\
\hline Slovenia & 12 & 12 & 0 & 0 & 0 \\
\hline Spain & 16 & 0 & 16 & 0 & 0 \\
\hline Sweden & 13 & 13 & 0 & 0 & 0 \\
\hline Switzerland & 19 & 19 & 0 & 0 & 0 \\
\hline Turkey & 13 & 0 & 13 & 0 & 0 \\
\hline Ukraine & 24 & 24 & 0 & 0 & 0 \\
\hline
\end{tabular}

Total Number of countries: 43

Total Number of Regions: 492 